(Aus dem Institute für experimentelle Pathologie an der deutschen Universität zu Prag.)

\title{
Die Bedeutung der Salze \\ der Ringer'schen Lösung für das isolirte Säugethierherz.
}

\section{Von}

Dr. E. Gross, Assistenten des Institutes.

(Mit 2 Textfiguren und Tafel II-IV.)

\section{Inhaltsübersicht.}

Seite

Einleitung . . . . . . . . . . . . . . . . . . 264

Untersuchungsmethode . . . . . . . . . . . . . . . . . 268

Einige Erfahrungen an dem mit Ring er'scher Lösung durchströmten Säuge-

thierherzen . . . . . . . . . . . . . . . . . . 271

Ausführung der Versuche . . . . . . . . . . . . . . . 276

Ergebnisse der Versuche nach der ersten Methode: Injection der einzelnen Salze 278 Ergebnisse der Versuche nach der zweiten Methode:

a) Weglassen eines Bestandtheiles der Ringer'schen Lösung . . . 290

b) Weglassen zweier (bezw. dreier) Bestandtheile der Ringer'schen Lösung . . . . . . . . . . . . . . . . . . . . . . 295

c) Uebersicht über die nach der zweiten Methode gewonnenen Ergebnisse 297

Ersatz des Natriumbicarbonats durch Natriumcarbonat oder Natronlauge . 299 Wirkung der Kohlensäure . . . . . . . . . . . . . . . . . . 301 Besprechung der gesammten Versuchsergebnisse und der einschlägigen

Literatur . . . . . . . . . . . . . . . . . . 302

Zusammenfassung der wichtigsten Versuchsergebnisse . . . . . . 316

\section{Einleitung.}

Die Untersuchungen am isolirten Froschherzen führten dazu, das ursprünglich zur Speisung benützte Blut durch andere Speisung'sflüssigkeiten zu ersetzen, um die Bedingungen für das Fortschlagen des isolirten Herzens und seine Ernährung kennen zu lernen. Mit physiologischer Kochsalzlösung durchspülte Herzen stehen bald still (Kronecker und Stirling), länger schlägt das Herz bei Durch- 
strömung mit alkalisch gemachter Kochsalzlösung (Merunowicz, Gaule, Stiénon); zur Erhaltung einer längeren Thätigkeit ist aber auch diese Mischung ungeeignet. Während eine Reihe von Autoren zu diesem Behufe Zufuhr organischen Materials für unerlässlich hält, zeigte Ring er (13), dass das Froschherz, von einer passend zusammengesetzten a n o r g a n is c h en Salzlösung durchspült, stundenlang fortschlagen könne, und dass eine solche Lösung Calciumund Kalium-Salze, ferner Kochsalz $(0,6 \%)$ und Natriumbicarbonat enthalten müsse.

Rusch (32) war der Erste, der bei dem nach der Methode L a ngend orff's (25) durchströmten Säugethierherzen statt des Blutes neben anderen Speisungsflüssigkeiten auch die Ringer'sche Lösung anwendete, und zwar in der von Ringer für das Froschherz empfohlenen Zusammensetzung, nur der Kochsalzgehalt wurde auf $0,8 \%$ erhöht.

Rusch fand, dass die Ringer'sche Lösung sowohl das mit physiologischer Kochsalzlösung zum Stillstand gebrachte, als auch das lediglich mit Kochsalzlösung ausgewaschene Säugethierherz (Katze) zum kraftvollen, rhythmischen Schlagen bringen und die Herzthätigkeit über eine halbe Stunde kräftig erhalten kann; dann wird dieselbe schwächer, um noch ebenso lange schwächer anzudauern. $\mathrm{Rusch}$ bestätigte somit für das Säugethierherz, dass dasselbe innerhalb gewisser Grenzen im Stande ist, ohne Zufuhr organisehen Nährmaterials allein durch Speisung mit einer anorganischen Salzlösung kräftig und frequent zu schlagen.

Locke (41) kam bei Ausdehnung seiner Froschherzversuche auf das Säugethier (Kaninchen) zu dem Ergebniss, dass Zusatz von Traubenzucker $(0,1 \%)$ und Sättigung mit Sauerstoff die Ringersche Lösung befähige, das Kaninchenherz 6-7 Stunden schlagend zu erhalten; er empfiehlt entsprechend der Analyse für das Kaninchenserum von Abderhalden (33) folgende Zusammensetzung der Ringer'schen Lösung: 0,01-0,03\% Natriumbicarbonat, 0,02 bis $0,024 \%$ Calciumchlorid, $0,02-0,42 \%$ Kaliumehlorid und 0,9 bis $1 \%$ Kochsalz.

Mit dieser nach Locke bereiteten Flüssigkeit hat $\mathrm{Kuliabko}$ (45) an Vogel- und Säugethierherzen gearbeitet; er zeigte u. A., dass die Herzthätigkeit noch lange nach dem Tode mittelst Durchspülung mit der L ocke'schen Flüssigkeit wiederhergestellt werden kann, wenn die Thiere auf Eis aufbewahrt werden. Es gelang ihm 
auch Menschenherzen viele Stunden nach dem Tode wieder zum Schlagen zu bringen (46).

Bei den im Institute seit Beginn des Wintersemesters 1902/03 von Herrn Prof. H. E. Hering gemachten Versuchen an isolirten Sängethierherzen (Kaninchen, Katzen, Hunde, Affen) wurden die Beobachtungen der genannten Autoren hinsichtlich der Ringer'schen Lösung im Wesentlichen bestätigt; doch erwies sich künstliche Sauerstoffzufuhr als entbehrlich, es genügte der gewöhnliche Luftgehalt der Flüssigkeit, den übrigens L o cke selbst bei geeigneter Temperatur für ausreichend fand. Damit stimmen auch die Beobachtungen Langendorff's, der das bei der Durchblutung aus den Hohlvenen abfliessende dunkle Blut lediglich mit Luft schüttelte und wieder verwendete, sowie die Untersuchungen von Strecker (36), der nachwies, dass schon ein verhältnissmässig geringer Gehalt des Blutes an Sauerstoff genügt, um das isolirte Herz eine Zeit lang am Leben und bei kräftiger Thätigkeit zu erhalten. Bezüglich des Traubenzuckers konnten wir in einem Versuche (Affenherz) die Angabe L ocke's bestätigen, dass die nach längerer Thätigkeit (in diesem Falle $1^{1 / 2}$ Stunden) allmählich schwächer werdenden Contractionen durch Zusatz von ca. $0,1 \%$ Glykose zur R ing er'schen Lösung wieder kräftiger wurden. Im Uebrigen kam es uns nicht auf allzu lange Dauer der Versuche an; wir verwendeten daher die Ringer'sche Lösung ohne künstliche Sauerstoffzufuhr und ohne Zucker. Die Concentration entsprach den von Locke für das Kaninchenherz angegebenen Procentzahlen; dabei ergab sich, dass diese Zusammensetzung auch für die anderen verwendeten Thierarten (Katze, Hund, Affe) sehr gute Erfolge lieferte und es nicht nöthig ist, sie je nach der Thierart zu modificiren. Wie aus den nachfolgenden Zahlen ersichtlich ist, unterscheiden sich die verschiedenen Sera auch nur unbedeutend in Gehalte an den in Betracht kommenden Salzen:

1000 Theile Blutserum enthalten nach A bderhalden (33):

$$
\mathrm{Na}_{2} \mathrm{O} \quad \mathrm{K}_{2} \mathrm{O} \quad \mathrm{CaO}
$$

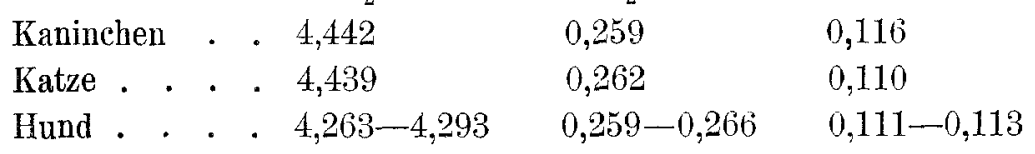

Wie H. E. Hering (52) früher bereits kurz mitgetheilt hat, konnte er an dem mit der Rin ger' schen Lösung durchspülten Säugethierherzen sämmtliche bekannten Wirkungen der extracardialen Herznerven beobachten; ferner bestätigte er die Angabe Kuliabko's 
über die Möglichkeit der Wiederbelebung des Herzens lange Zeit (his 54 Stunden) post mortem, wenn das Herz bezw. das ganze Thier in der Kälte in gefrorenem Zustande conservirt wurde, und fand, dass der Vagus noch 6 , der Accelerans noch 54 Stunden nach dem Tode des Thieres wirksam waren. Weiter benutzte H. E. H e ring (52) das mit der Ring er'schen Lösung durchströmte Säugethierherz zur Herstellung eines Kammerpräparats und fand, dass auf letzteres noch der Accelerans, nicht aber der Vagus mehr einwirkte.

Da über die Wirkung der Salze der Ringer' schen Lösung auf das isolirte Säugethierherz bisher keine Untersuchungen vorlagen, ging ich auf Anregung von Herrn Prof. H. E. Hering daran, diese Wirkungen zu studiren und der Frage näber zu treten, ob diese Salze sämmtlich zur Erhaltung der Thätigkeit des isolirten Herzens nothwendig sind.

Dass zu diesen Untersuchungen die Ringer'sche Lösung und nicht Blut als Durchströmungsflüssigkeit verwendet wurde, hat vor Allem darin seinen Grund, dass wir die Zusammensetzung der Ringer'schen Lösung genau kennen, was hinsichtlich des Blutes nicht bezüglich aller Bestandtheile gesagt werden kann. Zudem wäre bei Anwendung von Blut auch die Veränderung desselben oder einzelner Bestandtheile desselben (Blutkörperchen u. s. w.) durch die injicirten Substanzen in Betracht zu ziehen gewesen, was die Beurtheilung der Ergebnisse erschwert hätte. Endlich war auch die bei jedem Versuche zur Verfügung stehende Menge Blutes, selbst verdünnt, zu klein, da das mit verschiedenen Substanzen versetzte Blut nicht wieder zur Durchströmung hätte verwendet werden können.

Uebrigens sei schon hier erwähnt, dass - allerdings nicht zahlreiche - Versuche im Allgemeinen die Uebereinstimmung der Salzwirkungen bei Blutdurchspülung mit den bei Durchströmung mit Ringer'scher Lösung gewonnenen ergaben; nur die Dauer der Wirkung wich in beiden Fällen von einander $a b$, weil die Durchströmungsgeschwindigkeit des Blutes geringer ist als die der Ringerschen Lösung (siehe Anm. auf S. 270).

Die wesentlichen Ergebnisse der im Folgenden zu besprechenden Versuche theilte ich schon in der biologischen Section des Vereines "Lotos" am 27. Juni 1903 mit $^{1}$ ) und demonstrirte dieselben an einem mit Ringer'schen Lösung durchspülten Hundeherzen.

1) Siehe Prag. med. Wochenschrift 1903 Nr. 30. 


\section{Untersuchnimsmethode.}

Die Versuche wurden nach der von Langendorff (25) 1895 angegebenen, bekannten Methode vorgenommen, doch wich die Ausführung im Einzelnen von seiner Versuchsanordnung $a b$, und es sei daher im Folgenden die Zusammenstellung des in unserem Institute verwendeten Durchströmungsapparates und die Vorbereitung und Durchführung der Versuche kurz geschildert. Vor Allem ist hervor-

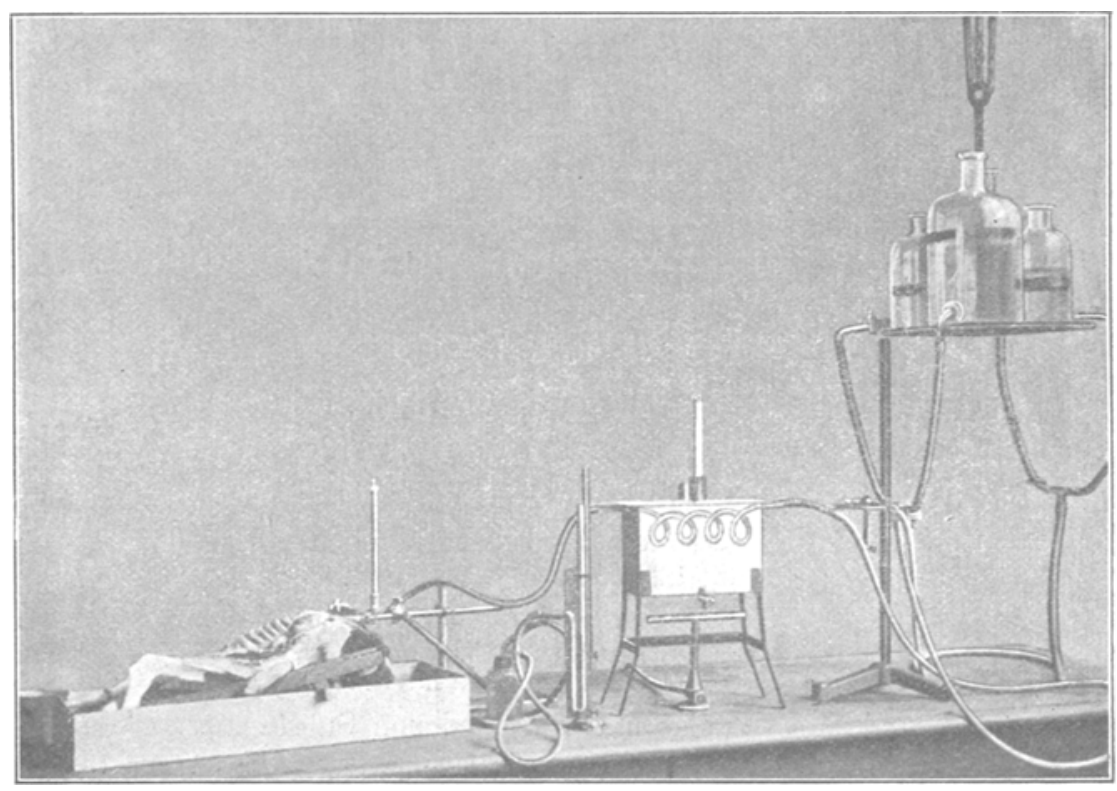

Fig. 1.

zuheben, dass das Herz nicht herausgeschnitten, sondern in situ belassen wurde, so dass auch der Zusammenhang mit den extracardialen Nerven erhalten war.

Der Durchströmungsapparat (Fig. 1) besteht aus einem System von zwei grösseren, 5 Liter, und zwei kleineren, 2 Liter fassenden Flaschen mit seitenständigem Bodentubus, in denen sich Stöpsel mit Glashähnen armirt befinden. Je eine grössere und kleinere Flasche stehen mittelst Gummischläuchen durch die horizontalen Enden eines $T$-Rohres mit einander in Communication, die verticalen Enden der beiden $T$-Rohre sind mit Gummischläuchen versehen, die mittelst $Y$-förmiger Canüle zu einem Glasschlangenrohr führen. Das- 
selbe befindet sich in einem Wasserbad, das durch eine Gasflamme auf eine bestimmte Temperatur gebracht wird; diese ist an einem Thermometer ablesbar, welches in das Wasserbad eintaucht. Die Ausflussmündung des Schlangenrohres führt bei $c$ (Fig. 2) zu einem Dreiweghahn $(a)$, der bei $b$ mit einem Quecksilbermanometer behufs

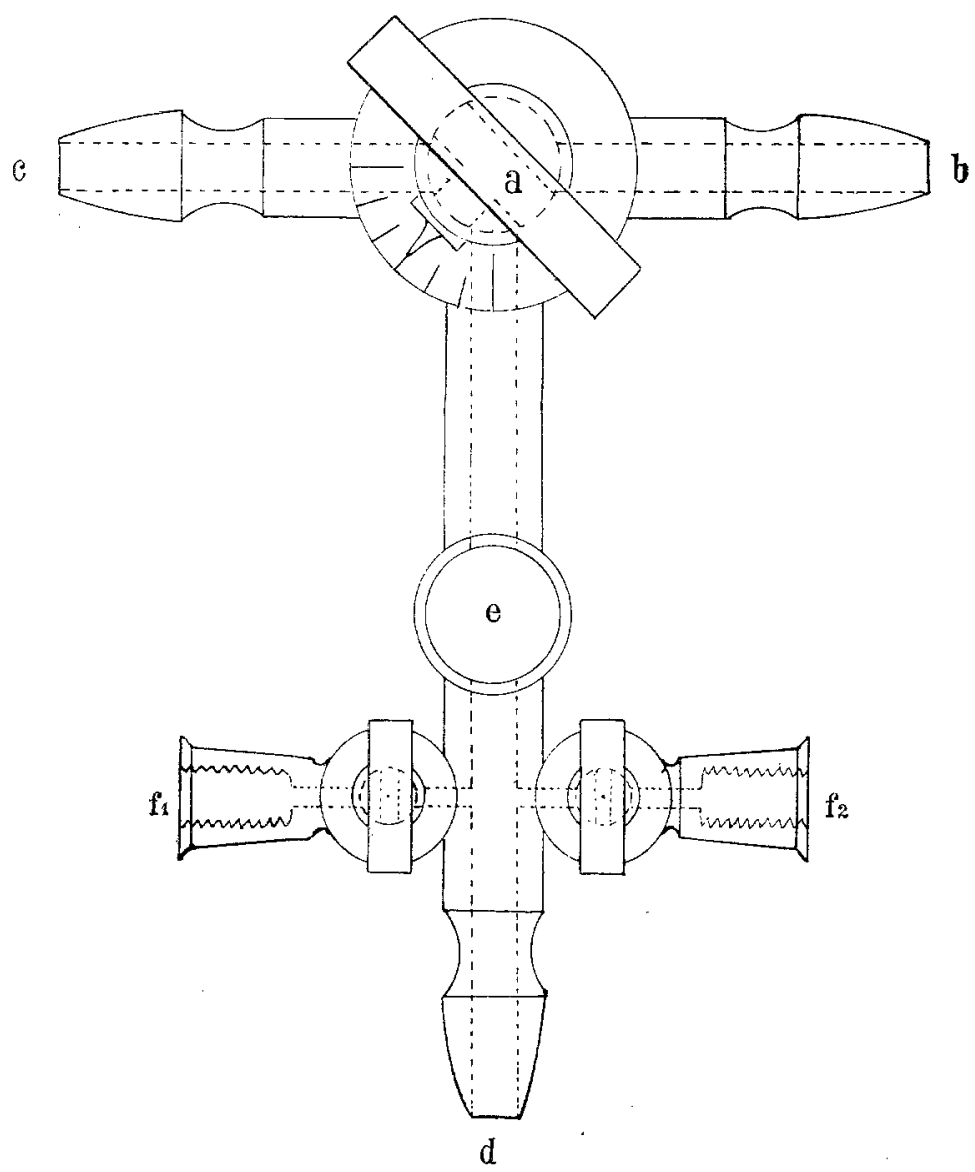

Fig. 2.

Ablesung des Druckes und bei $d$ mit der Herzcanüle verbunden ist. An dem Rohre, welches die Verbindung mit der Herzcanüle herstellt, sind, einander gegenüberliegend, zwei Metallhähne $\left(f_{1}\right.$ und $f_{2}$ ) angebracht, in welche gläserne Injectionsspritzen eingeschraubt werden können; ferner ist in dieses Rohr ein Thermometer (e) eingefügt, welches die Temperatur der in's Herz einfliessenden Flüssig- 
keit $12 \mathrm{~cm}$ vor dem Eintritt in die Aorta angibt. Diese Temperatur ist von der des Wasserbades wegen der unterwegs stattfindenden Abkühlung je nach der Durchflussgeschwindigkeit mehr oder weniger verschieden. Die Durchflussmenge kann durch die Stellung des Dreiweghahnes variirt und der Grad der Oeffnung desselben an einer Theilscheibe abgelesen werden.

Zur Erzielung eines bestimmten Druckes ist das Flaschensystem an einem schwebenden Gestell angebracht, das mittelst eines Flaschenzuges verschieden hoch eingestellt werden kann. Das ganze System muss mit der Durchspülungsflüssigkeit gefüllt sein, wobei Luftblasen in den Schläuchen und in der Glasschlange zu vermeiden sind; in der letzteren bilden sich auch bisweilen beim anfänglichen Erwärmen der stagnirenden Flüssigkeit Luftblasen, die vor dem Einbinden der Canüle durch Abfluss entfernt werden müssen.

Die Versuchsthiere wurden zumeist dureh Verblutung aus den Karotiden getödtet, Hunde und Katzen in Aether-Chloroformnarkose (wenig Chloroform, um das Herz weniger zu schädigen).

Bei Kaninchen ist wegen der Gefahr der Entstehung einer Luftembolie das Anschneiden der Venen besonders zu vermeiden. Nach Ablauf des letzten terminalen Athemzuges wird das Sternum und ein Theil der Rippen entfernt (damit das Herz und die Lungen möglichst freiliegen) und die Lungen knapp an den Wurzeln der grossen Bronchien abgeschnitten. Hierauf werden die Baucheingeweide mit dem $Z$ werchfell entfernt. Die untere Hohlvene wird knapp oberhalb des Zwerchfells durchtrennt, um ein möglichst grosses Stück am Herzen zu belassen; in die Hohlvene kann eine Glascanüle behufs eventueller Messung der in der Zeiteinheit ausströmenden Flüssigkeit ${ }^{1}$ ) oder chemischer Untersuchung derselben eingebunden

1) H. E. Hering (Prag. med. Wochenschr. 1903 Nr. 30) machte darauf aufmerksam, dass, wie entsprechende Versuche ergeben haben, das künstlich durchströmte Herz sich zu Studien über den Widerstand der Blutbahn bezw. äber die Viscosität des Blutes u. s. w. eignet. Durchströmt man das Herz statt mit Ring e r scher Lösung mit Blut, so fliesst letzteres, auch wenn es stark verdünnt ist (z. B. 1 Theil Blut, 2 Theile Ringer) deutlich viel langsamer in der Zeiteinheit durch die Gefässe des Herzens als die Ringer'sche Lösung. Setzt man zur Ringerschen Lösung z. B. $2 \%$ Gummi arabicum, so fliesst es auch langsamer als reine R ing e rlösung.

Einschlägige Untersuchungen hat man bis jetzt nur mit künstlichen, nicht aber mit natürlichen Capillaren gemacht. Aus letzterem Grunde, wie auch aus dem, dass bei der vorliegenden Methode die Thätigkeit des Herzens gleich- 
werden. Schliesslich wird das Pericard eröfnet, die Aorta freigelegt und ein Faden um dieselbe geschlungen.

Es folgt dann noch eventuell die Präparation der Herznerven, worauf das ganze Thier auf dem Aufspannbrette in einen vor dem Durchströmungsapparate befindlichen Zinkblechkasten gesetzt wird, in welchen die aus dem rechten Herzen kommende Flüssigkeit abfliesst; diese wurde, wie erwähnt, nicht wieder zum Durchströmen verwendet.

Das Einbinden der Canüle in die Aorta erfolgt bei constantem Strömen der unter Druck stehenden und entsprechend erwärmten Flüssigkeit; vorher lässt man etwas Flüssigkeit in die Aorta einlaufen, um etwaige Blutgerinnsel $\mathrm{zu}$ entfernen. Sonst vermeidet man am besten jedes Anfassen oder Ausdrücken des Herzens, da namentlich bei Hundeherzen hierdurch leicht Flimmern entsteht. Das vorherige Durchspülen mit Kochsalzlösung ist unnöthig, in unseren Versuchen liessen wir direct die Ringer'sche Lösung durchströmen; die Herzwände sind rasch durchspült, das Herz erhält eine blassere Farbe und fängt entweder sofort oder nach einiger Zeit kräftig zu schlagen an. Die Verzeichnung der Thätigkeit der einzelnen Herzabtheilungen erfolgte nach der Knoll' schen Suspensionsmethode, die Hebel schrieben auf der berussten Trommel eines Hering'schen Kymographions.

Bemerkt sei, dass zwischen dem Tode des Thieres und der Einbindung der Canüle ca. ${ }^{1 / 4}-1 / 2$ Stunde verstrich.

\section{Einige Erfahrungen an dem mit Ringer'scher Lösung durchströmten Sängethierherzen.}

Die meisten mit Ringer'scher Lösung wiederbelebten Herzen schlagen nach der Durchströmung rhythmisch und kräftig, in normaler Folge von Vorhof und Ventrikel; die Herzaction unterscheidet sich in ihrer Stärke, wie Controlversuche zeigten, zu Beginn der Versuche nicht wesentlich von der bei Durchströmung mit defibrinirtem, mit zwei Theilen Ringer-Lösung verdünntem Blute. - Im Verlaufe längerer Versuche zeigte sich oft eine Abnahme der Contractionsgrösse, und in diesem Stadium erwies sich Zufuhr von Blut als sehr

zeitig einen leicht feststellbaren Aufschluss gibt über das Maass der Function des durchströmten Organs, empfiehlt $\mathrm{H}$ er ing das künstlich durchströmte schlagende Säugethierherz zu derartigen Versuchen. 
vortheilhaft. - In einigen Versuchen erlahmten die Ventrikel nach längerer Zeit in ihrer Kraft, die sichtbaren Ausschläge wurden kleiner. Dies betraf häufiger nur den linken Ventrikel; während der rechte sehr lange kräftig fortpulsirte, verzeichnete der linke dann keine Ausschläge mehr, er wurde auch grösser, scheinbar ausgedehnt, obwohl späteres Anschneiden ergab, dass seine Höble leer war. Diese Volumszunahme betrifft nur die Wand der Ventrikel, gleichzeitig kommt es auch zu einer Trübung des Pericards und des Bindegewebes entlang den grossen Gefässen, Abhebung desselben in Form von Bläschen, das Herz ist weisslich, mit Flüssigkeitströpfchen wie beschlagen; wird das Herz später aufgeschnitten, so sieht man auch am Endocard die opake Färbung, die Muskulatur ist normal gefärbt, aber stark wasserhaltig.

Der grössere Wassergehalt der Kammerwand dürfte im Wesentlichen seinen Grund in einer stärkeren Durchlässigkeit der Gefässe haben.

Diese Veränderung des Herzens, zu deren Erklärung eingehendere Untersuchungen nöthig sind, kann schon rein mechanisch die Contractionsgrösse des Herzens ungünstig beeinflussen. Denn sperrt man den Zufluss ab, oder injicirt man Stoffe, die sonst Verstärkung der Herzaction hervorrufen, so sieht man solche Herzen noch sehr kräftige Contractionen verzeichnen, es ist nur der höhere Wassergehalt der Kammerwand, der die Systolen nicht oder schwächer zum Ausdruck kommen lässt. -

Bei einigen Versuchsthieren (Kaninchen) kam das Herz trotz mehr als halbstündiger Durchspülung überhaupt nicht zum Schlagen oder stand nach ein paar schwachen Schlägen definitiv still.

Im Ganzen war dies bei 7 von 50 verwendeten Kaninchen der Fall, hiervon wurden bei 2 nachträglich Blutcoagula in der Aorta oberhalb der Coronargefässe und in diese hineinreichend gefunden. Bei den 5 übrigen ergab die Section kemen Anhaltspunkt für das abnorme Verhalten der Herzen.

Auch die Tödtungsart kann an demselben nicht Schuld gewesen sein, denn auch als dieselbe modificirt wurde, kam derselbe Misserfolg vor. Von den 43 Kaninchen mit positivem Ergebniss waren 25 verblutet, 9 durch Erstickung in Folge Anlegung eines beiderseitigen Pneumothorax, 2 durch Erstickung (Athmen aus einer thierischen Blase) und 6 dureh intravenöse Injection letaler Kaliumdosen getödtet worden, zudem war der Verlauf (Krämpfe u. s. w.) in den einzelnen 
Fällen verschieden; von den 5 negativen Fällen wurden 3 verblutet, 1 erstickt (Pneumothorax) und 1 mit Kaliumchlorid vergiftet.

Eher dürften individuelle Verhältnisse hierbei mitgewirkt haben (Widerstandsfähigkeit des Herzens), so wurde bei 3 hinter einander auf verschiedene Weise - Verblutung, Erstickung, Kaliumvergiftung getödteten Kaninchen aus demselben Stalle keine Wiederbelebung des Herzens erzielt.

Bei den 11 zur Durchspülung des Herzens verwendeten Katzen und 52 Hunden, die in Narkose aufgebunden und verblutet wurden (mit der Verblutung wurde immer gewartet, bis die Reflexe wiedergekehrt waren), kam es stets prompt zum Wiederschlagen des ganzen Herzens, wesshalb zuletzt fast nur Hunde verwendet wurden.

Erwähnt sei, dass auch die Herzen von Thieren, die in der Chloroformnarkose verendet waren, sich wieder beleben liessen.

Die 'Schlagfrequenz der mit der Ringer'schen Lösung durchspülten Säugethierherzen war bei unseren Versuchen meist etwas geringer als die normaler Herzen der betreffenden Thierspecies, was im Wesentlichen auf die niedrige Temperatur, bei der die Herzen schlugen, zurückzuführen sein wird.

Dieselbe betrug gewöhnlich zwischen $30-35^{\circ}$ und wurde möglichst constant erhalten.

Wie dies - im Sommer - auf eine sehr einfache Weise durch lange Zeit möglich ist, zeigte uns ein Versuch am Hundeherzen, bei dem die Glassehlange aus dem Wasserbade gehoben wurde; die Temperatur sank auf $23^{1 / 2}{ }^{0}$ und blieb durch $1^{1 / 2}$ Stunden constant, dabei schlug das Herz $48 \mathrm{Mal}$ in der Minute kräftig und regelmässig, während es anfangs $72 \mathrm{Mal}$ (bei $30^{\circ}$ ) geschlagen hatte. Die Höhe der Aussehläge stieg anfangs in Folge der Abnahme der Schlagfrequenz, dann wurde dieser Factor durch die Wirkung der Abkühlung compensirt, und die Ausschläge bewegten sich in den früheren Grenzen.

Von Unregelmässigkeiten wurden an dem mit Ringerscher Lösung durchspülten Säugethierherzen die bekannten Formen: Auftreten von Extrasystolen (Bigemini, Trigemini u. s. w.), Ausfallen von Ventrikelschlägen bei regelmässig fortschlagenden Vorhöfen und Alternans beobachtet.

Vom Alternans, der bei Hunden und Kaninchen relativ häufig spontan vorkam, wurden mehrere Formen beobachtet, die H. E. Hering auch am normalen Herzen bereits gefunden hat und demnächst 
ausführlich mitzutheilen gedenkt. H. E. Hering unterscheidet nämlich bisher folgende beobachtete Formen von Alternans: a) Alterniren der Contractionsgrösse an Vorhof und Ventrikel gleichsinnig, b) die grössere Contraction am Vorhof geht der kleineren am Ventrikel voraus, c) der Vorhof macht gleich grosse Contractionen, nur der Ventrikel schlägt im Alternans, d) der Vorhof schlägt im Alternans, der Ventrikel nicht, e) Fortbestehen des Alternans am Ventrikel, trotzdem nur jeder zweite Vorhofsehlag beantwortet wird.

Der Alternans konnte bemerkenswerther Weise in manchen Fällen trotz Einwirkung anregender Ursachen (Acceleransreizung, Injection verschiedener Substanzen, die verstärkend wirken, wie $\mathrm{CaCl}_{2}, \mathrm{NaHCO}_{3}$ ) nicht zum Verschwinden gebracht werden, während hierdurch in anderen Versuchen bei Verstärkung rer Herzthätigkeit besonders die kleinere Systole zunahm und der Alternans vorübergehend verschwand. Bisweilen bestand zu Beginn der Durchströmung Alternans, nach einiger Zeit wurden die Contractionen durch stete Zunahme der kleineren Systole gleich gross. Ueber einige Ursachen des Entstehens sowie Verschwindens der anderen Unregelmässigkeiten, soweit sie nicht spontan kamen, soll im speciellen Theil noch die Rede sein. -

Ferner kummt es besonders bei Hundeherzen trotz aller Vorsicht nicht selten zu spontanem Flimmern, das bei Fortströmen der Ringer'schen Lösung nicht verschwindet.

Bei Hundeherzen sahen wir nur einmal ein durch faradische Reizung in Flimmern gerathenes Herz von selbst wieder zu coordinirtem Schlagen übergehen, während dies - wie auch sonst bekannt - bei Kaninchen nicht selten ist.

Langend orff (47) fand, dass das in Flimmern gerathene, nach seiner Methode isolirte Herz durch Absperren des Blutstromes zur Ruhe kommt, worauf es nach Freigabe des Blutstromes wieder normal schlägt.

Ein rascher wirkendes, von uns oft und stets mit Erfolg verwendetes Mittel, spontan entstandenes oder künstlich (durch mechanische oder elektrische Reizung) erzeugtes Flimmern bei bestehender Durchströmung zu beseitigen, fand H. E. Hering (52) in der Injection einer Dosis Kalium $(\mathrm{KCl})$, welehe so gross sein muss, um Herzstillstand herbeizufübren, dann folgt dem Stillstand spontan coordinirtes Schlagen des Herzens.

Der Eintritt einer Luftembolie ist, da die Luftbläschen mit 
der Flussigkeit in die Coronargefässe eindringen und dieselben verlegen, an dem Leerwerden der oberfächlich unter dem Epicard verlaufenden Gefässe zu erkennen, welche als zarte, weisse Streifen hervortreten; dabei sieht man oft direct die Luftbläschen in den Gefässen.

Die Thätigkeit eines solchen Herzens ist natürlich sehr gestört, da die nicht durchströmten Partien sich schwächer contrahiren, dadurch werden die Gesammtcontractionen kleiner. Hierbei wird das Herz gewöhnlich grösser, manchmal auch nur der von der Embolie betroffene Ventrikel.

In einigen Fällen trat im Anschlusse an eine Luftembolie Flimmern ein.

Es ist ferner hervorzuheben, dass in solchen Fällen bei fortgesetzter Durchströmung, namentlich unter erhöhtem Druck, die Luftbläschen allmählich aus den Arterien verschwanden, die Arterien sich wieder mit Flüssigkeit füllten und das Herz wieder zu kräftiger Thätigkeit gelangte. -

Schliesslich sei noch bemerkt, dass wir die von Rusch (32) beschriebene, von ihm als "paradoxe Pulssteigerung" bezeichnete Erscheinung, dass nach Unterbrechung der Circulation des mit Ringer'scher Lösung durchströmten isolirten Säugethierherzens eine allerdings rasch vorübergehende Verstärkung der Herzaction auftritt, unter denselben Umständen ebenfalls beobachteten. Wir erklären uns dieses Phänomen ebenso wie $\mathrm{Rusch}$ als durch mechanische Ursachen bedingt, indem die bei der Durchströmung prall gefüllten Herzgefässe dem Zustandekommen der Systole einen gewissen Widerstand entgegensetzen, der sich nach Abstellung des Stromes natürlich vermindert. Dass es sich hierbei, wie Langendorff (47) später meinte, um eine dyspnoische Erscheinung handle, bedingt durch die primär die Erregbarkeit des Herzmuskels steigernde Anhäufung von Erstickungsproducten, wobei er in erster Linie an die Kohlensäure denkt, - balten wir nicht für wabrscheinlich ${ }^{1}$ ).

Denn erstens tritt diese Aenderung so plötzlich ein, dass sie nicht gut auf die Anhäufung von Erstickungsproducten, die sich nicht so rasch geltend machen würde, bezogen werden kann. (Speciell auf die Kohlensäure können wir die Erscheinung auf Grund unserer später mitzutheilenden Untersuchungen nicht beziehen.)

1) Die von Leo Schirrmacher (42) gegen die Erklärung von Rusch erhobenen Einwände sind nicht überzeugend. 
Und zweitens beobachten wir unter den genannten Umständen lediglich eine Grössenänderung ohne Aenderung der Schlagfolge, welche man bei Erstickung des Herzens gewöhnlich nicht vermisst.

\section{Ausführung der Versuche.}

Bei den Untersuchungen über die Wirkungen der Salze wurden folgende zwei Wege eingeschlagen.

Bei der ersten Methode wurde das isolirte Herz mit der Ringer'schen Lösung $\left(0,03 \% \mathrm{NaHCO}_{3}, 0,042 \% \mathrm{KCl}, 0,024 \%\right.$ $\mathrm{CaCl}_{2}$ und $\left.0,9-1 \% \mathrm{NaCl}\right)$ durchspült und durch die seitlichen Ansätze der Herzcanüle die einzelnen Salze in destillirtem Wasser gelöst mittelst gläserner, $12 \mathrm{ccm}$ fassender Injectionsspritzen in's Herz injicirt. Bei dieser Methode wird durch die Injection der Salzgehalt der durchfliessenden Ringer'schen Lösung vorübergehend erhöht.

Von Bedeutung bei der Ausführung der Injectionen ist die Geschwindigkeit, mit der dieselbe vorgenommen wird, worauf meines Wissens bei ähnlichen Untersuchungen bisher zu wenig geachtet wurde. Je rascher nämlich die Injection erfolgt, um so intensiver und länger dauernd ist bei gleich grossen Dosen die Wirkung, weil die Menge der in der Zeiteinheit in's Herz gelangenden Sub$\operatorname{stanz}$ grösser wird, was sich auch aus entsprechenden Versuchen ergab, wie später an Beispielen gezeigt werden wird ${ }^{1}$ ). Aus dem genannten Grunde wurde auch in unseren Versuchen stets Anfang und Ende jeder Injection durch Marken nach Kommando registrirt, die Marken kommen daher auch um ein Geringes später.

Ausser von der Geschwindigkeit der Injection hängt die auftretende Wirkung in ihrer Stärke und Dauer auch von der absoluten Menge des applicirten Salzes und der Natur desselben ab; ferner von der Geschwindigkeit des Durchflusses der durchströmenden Ringe r'schen Lösung, welche wieder durch verschiedene Factoren variirt wird, wie Verschiedenheit des Druckes, verschiedene Grösse der Herzen der einzelnen Thierspecies und -Individuen, sowie verschiedene Stärke und Frequenz der Herzthätigkeit. -

Das Einschrauben der vollständig gefültten Spritzen in die mit Hähnen versehenen seitlichen Ansätze erfolgte, um das Hineingelangen

1) Wenn eine grössere Menge Flüssigkeit zu rasch in's Herz injicirt wird, kommt es leicht ganz vorübergehend zu einer Deformirung der Curve aus rein mechanischen Gründen. 
von Luft in die Canüle zu vermeiden, immer bei geöffnetem Hahne, damit die unter Druck abfliessende Flüssigkeit die im Hahne befindliche Luft verdrängt.

Bei der zweiten Methode wurden aus der Ringer'schen Lösung ein, zwei oder drei Bestandtheile weggelassen und der Einfluss einer solchen modificirten, z. B. kalium- oder calciumfreien Lösung, die im Uebrigen auch procentisch genau so zusammengesetzt war wie die gewöhnliche Ring er'sche Lösung, mit der letzteren verglichen.

$\mathrm{Zu}$ diesem Behufe wurden die beiden grösseren Flaschen des Systems mit Ringer'scher Lösung gefüllt, in die beiden anderen wurde - nachdem die verbindenden Schläuche durch Oeffnen der Häbne ebenfalls mit Ring er'scher Lösung vollständig luftfrei gefüllt waren - die zu untersuchende Flüssigkeit gefüllt. Es wurde nun das Herz durch Ringer'sche Flüssigkeit wiederbelebt und, wenn es kräftig schlug, die modificirte Flüssigkeit statt der Ringer'schen eingeschaltet. Der Wechsel erfolgte durch Oeffnung bezw. Schliessung der Häbne an dem bodenständigen Tubus der Flasche; es musste sonach erst die gesammte im Schlauch und in der Glasschlange befindliche Ringer'sche Lösung durch das Herz abströmen, ehe die zu untersuchende modificirte Flüssigkeit hinein gelangte. Der Zeitpunkt, wenn dies geschah, wurde lediglich nach dem Eintritte der stets deutlich auftretenden Wirkung beurtheilt ${ }^{1}$ ).

Die Finrichtung liess es auch zu, nach dei einen modificirten Lösung eine zweite oder dritte dem Herzen zufliessen zu lassen, auch war durch Dreiweghähne in den zwei Schläuchen, welche sich durch das Y-Rohr zur Glasschlange vereinigten, dafür gesorgt, dass die eine oder andere Flasche wäbrend des Versuches ausgeleert und mit einer anderen Flüssigkeit gefüllt werden konnte.

Es sei noch ausdrücklich darauf aufmerksam gemacht, dass man die verzeichneten Contractionshöhen der Curven bei den verschiedenen Versuchen unter einander nicht vergleichen darf, da die Suspension bei den verschiedenen Herzen nicht immer an ein und demselben Punkte erfolgte. Es ist daher nur möglich, die an ein und dem-

1) Eventuell kann man, um genau den Zeitpunkt festzustellen, in dem die zu untersuchende Flüssigkeit in's Herz gelangt, dieselbe mit einem indifferenten Farbstoff färben. 
selben Individuum bei einem Versuche und derselben Suspension auftretenden Aenderungen der Contractionen mit einander in Vergleich zu ziehen.

\section{Ergebnisse der Versuche nach der ersten Methode.}

$$
\text { (Injection der einzelnen Salze). }
$$

Kaliumchlorid. Die Wirkung des Kaliumchlorids in hinreichender Menge besteht in einer Abschwächung der Herzthätigkeit, die sich in Verkleinerung der Contractionen und Abnahme der Frequenz, bei grösseren Dosen in einem vollständigen Aufhören der Herzaction - Stillstand des Herzens in Diastole - äussert. Diese Wirkung geht, wie bei der Injection aller verwendeten Substanzen, je nach der Dosis in längerer oder kürzerer Zeit vorüber, da fortdauernd Ring er'sche Lösung nachfliesst. (Fig. 1, 2 und 3, Taf. II.)

Was die Grösse der wirksamen Dosen anlangt, kann man bei Kaninchenherzen mit $3 \mathrm{cem}$ einer $1 / 10$ norm. Lösung $(=0,74 \%)$ $\mathrm{KCl}$ einen 12-30" langen Stillstand erzielen, während $1-2 \mathrm{~cm}$ derselben Lösung Verkleinerung und Verlangsamung bewirken; bei Hundeherzen sind entsprechend grössere Dosen nöthig. Wie sehr es dabei auf die Geschwindigkeit, mit der die Injection erfolgt, ankommt, zeigen folgende Angaben, die einem Versuche am Hundeherzen (5. März 1903, Vers. Nr. XVII) entnommen sind.

$11^{\mathrm{h}} 39^{\prime}$. Das ganze Herz schlägt kräftig, $120 \mathrm{Mal}$ in einer Minute, Ventrikelausschläge $20 \mathrm{~mm}$ hoch.

Injection von $6 \mathrm{ccm} \mathrm{KCl-Lösung} \mathrm{1/10} \mathrm{n.} \mathrm{(Dauer} \mathrm{der} \mathrm{Injection} \mathrm{4"):}$

Die Contractionsgrösse sinkt auf $8 \mathrm{~mm}$, dann erfolgt Stillstand des ganzen Herzens $12 \frac{1}{2} 2^{\prime \prime}$ lang, darauf eine kräftige Contraction, der kleinere folgen, die allmählich auf $19 \mathrm{~mm}$ zunehmen. Frequenz nach dem Stillstand $9 \frac{1 / 2}{2}$ in $5^{\prime \prime}$ (117 in $\left.1^{\prime}\right)$, später wieder 120 in $1^{\prime}$ (Temp. 34,5\%).

$11^{\text {h }} 42^{\prime}$. Injection von $5 \mathrm{ccm}$ derselben Lösung (Dauer $4 "$ ), Stillstand $12^{1 / 2 \prime 2}$.

$11^{\mathrm{h}} 44^{\prime}$. Injection von $7 \mathrm{ccm}$ (Dauer $2^{1 / 2}$ "), Stillstand dauert $27^{\prime \prime}$.

$11^{\mathrm{h}} 46^{\prime}$. Injection von $61^{1 / 2} \mathrm{ccm}$ (Dauer $10^{1 / 2}$ ), es tritt kein Stillstand, sondern nur Verlangsamung und Verkleinerung der Contractionen von 181/2 auf $10 \mathrm{~mm}$ ein.

$11^{\mathrm{h}} 47^{\prime}$. Injection von $5 \mathrm{ccm}$ (Dauer $\left.1^{\prime \prime}\right)$, Stillstand von $9^{\prime \prime}$ Dauer.

Sehr geringe Mengen von $\mathrm{KCl}$ (wenige Kubikcentimeter $1 / 30$ norm. bis 1/20 norm. Lösung) beeinflussen die Herzthätigkeit entweder nicht merklich oder im Sinne der Abschwächung, niemals wurde bei den vielen Versuchen Verstärkung und Beschleunigung beobachtet, wohl 
kam es aber vor, dass entsprechend einer bedeutenden Verlangsamung die Ausschläge an Grösse etwas zunahmen.

Die Herzen der verwendeten Versuchsthiere vertrugen oft sehr grosse Dosen von Kalium auf ein Mal ohne besondere Schädigung; so wurden bei einem Hundeherzen (6. Februar 1903, Vers. Nr. 3) 4 ccm einer $7,4 \%$ igen Lösung von $\mathrm{KCl}$ injicirt $(0,03 \mathrm{~g} \mathrm{KCl})$, worauf ein eine halbe Minute dauernder Stillstand und danach wieder kräftige normale Herzthätigkeit erfolgte. Bei einem Kaninchen (4. Februar 1902, Vers. Nr. 1) wurden $3 \mathrm{cem}$ einer $10 \%$ igen KCl-Lösung injicirt, der Stillstand dauerte bier drei Minuten.

In den Versuchen, wo ein Stillstand des Herzens durch Kalium erfolgte, war der Eintritt und der Ablauf desselben im Einzelnen nicht immer gleichartig.

Meist ging dem Stillstand ein kurzes Stadium voraus, in dem die Höhe der Contractionen schon etwas abnabm; erfolgte die Injection etwas rascher, kam also die ganze Giftdosis schneller zur Wirkung, so setzte der Stillstand unvermittelt ein.

Auch die Wiederaufnahme der Herzaction war nicht immer gleich; gewöhnlich erfolgte nach dem Stillstand eine Contraction, die grösser war als die vorausgehenden (wie dies auch sonst nach Herzpausen gewöhnlich der Fall ist); die auf diese grosse Contraction folgenden Contractionen waren viel kleinèr als die dem Stillstande vorausgehenden und uahmen erst allmählich an Grösse zu. (Fig. 1 Taf. II.) Bei einigen Injectionen waren zwischen der grossen, dem Stillstand folgenden und den kleinen zwei bis drei Contractionen von absteigender Grösse (Treppe) eingeschaltet. - Es kam aber auch vor, dass die erste Systole nach der Pause zwar grösser war als die folgenden, aber kleiner als die dem Stillstand vorangehenden Contractionen.

Die Frequenz war nach der Pause meist noch verlangsamt, erst allmählich stellte sich die frühere Frequenz wieder her.

Auch auf die einzelnen Herzabtheilungen war die Wirkung nicht immer die gleiche.

Meist betraf der Stillstand das ganze Herz. I $u$ diesem Falle begann gewöhnlich nach dem Stillstand das ganze Herz in normaler Succession (Vorhöfe vor den Ventrikeln) zu schlagen. Es kam aber auch vor, dass zuerst die Vorhöfe schlugen und die Ventrikel erst nach einiger Zeit die Thätigkeit aufnahmen. Auch das Umgekehrte wurde einige Mal beobachtet, zuerst Schlagen der Ventrikel, nachher erst Schlagen der Vorhöfe. 
Bei einigen Versuchen kam es nicht zum Stillstande des ganzen Herzens, es standen nur die Kammern still, während die Vorhöfe weiterschlugen.

Bei einem Herzen (Hund) trat das Umgekehrte ein: Stillstand der Vorhöfe bei weiterschlagenden Kammern. (Fig. 2 auf Taf. II.) In diesem Falle wurden folgende Injectionen von $\mathrm{KCl}$ vorgenommen:

1. $8 \mathrm{ccm} 1 / 10$ n. Dauer der Injection 51/2". Wirkung: Stillstand der Vorhöfe und des Ventrikels $9^{\prime \prime}$.

2. $7 \mathrm{ccm} 1 / 10 \mathrm{n}$. Dauer der Injection $9^{1 / 4^{\prime \prime}}$. Wirkung: Stillstand der Vorhöfe allein $81 / 2 "$.

3. $5 \mathrm{ccm} 1 / 10$ n. Dauer der Injection 9". Wirkung: Stillstand der Vorhöfe allein 4.

4. $4 \mathrm{ccm} 1 / 5 \mathrm{n}$. Dauer der Injection $81 / 2 "$. Wirkung: Stillstand der Vorhöfe allein $81 / 2 "$.

5. $6 \mathrm{ccm} 1 / 5 \mathrm{n}$. Dauer der Injection $6^{1 / 2}$ ". Wirkung: Stillstand der Vorhöfe allein $25^{1 / 2}{ }^{\prime \prime}$.

Bei der 2.-4. Injection schlugen die Kammern während des Stillstandes des Vorhofes im selben Tempo und ohne wesentliche Aenderung der Höhe weiter, nur bei der 5 . Injection, die dem Herzen eine grosse Kaliumdosis in $6^{1 / 2} \mathbf{2}^{\prime \prime}$ zuführte, erfolgte eine Beeinflussung der Ventrikel, indem ihre Contractionen bedeutend verlangsamt und verkleinert waren.

Zwischen der 1 . KCl-Injection und den folgenden wurden Injectionen von Calciumchlorid vorgenommen; da dieses, wie wir später noch ausführlich zeigen werden, die Reactionsfähigkeit des Herzens, besonders aber der Ventrikel, günstig beeinflusst und speciell dem Kalium antagonistiseh wirkt, könnte die Divergenz in der Wirkung des Kaliums bei der 1. Injection von der bei den folgenden durch erhöhte Resistenz der Ventrikel in Folge einer Ca-Nachwirkung erklärt werden.

Da aber analoge Fälle dieses Verhalten nicht ergaben, ist es nicht unwahrscheinlich, dass die genannte Wirkung auf abn orme Gefäss vertheil ung ${ }^{1}$ ) zurückzuführen ist, so dass von der injicirten Substanz

1) Bei einem Versuche am Hundeherzen wurden einige Kubikcentimeter reinen Chlor oforms in die Herzcanüle injicirt, worauf der linke Ventrikel, der linke Vorhof und ein kleiner Theil des rechten Ventrikels und rechten Vorhofes weisslichgelb verfärbt und starr wurden. Die von dieser Veränderung (Eiweissgerinnung) betroffenen Theile standen still, während der basale Theil des rechten 
bei kleinerer Dosis und langsamerer Injection (oben 2., 3., 4. Injection) mehr in die Vorhöfe als in die Ventrikel gelangte und daher letztere von der Kinwirkung frei blieben, bei grösserer Dosis und rascherer Injection (Fall 1 und 5) auch die Ventrikel von der Wirkung mehr oder weniger betroffen wurden. Hierfür spricht auch, dass die in diesem Versuche applicirten anderen Substanzen ebenfalls viel stärker auf den Vorhof als auf den Ventrikel wirkten.

Dass bei den Injectionen 2-4 der Rhythmus der Ventrikel bei Stillstand der Vorhöfe unverändert blieb, spricht dafür, dass die Erregung vom Orte der normalen Reizbildung $\mathrm{zu}$ den Ventrikeln gelangte, während die Vorböfe keine merkbaren Contractionen verzeichneten. -

Die beschriebenen Veränderungen der Herzthätigkeit unter der Einwirkung des Kaliums sind denen bei Vagusreizung sehr ähnlich. Auch Stillstand der Ventrikel bei Weiterschlagen der Vorhöfe sowie das Umgekehrte: Stillstand der Vorhöfe bei verlangsamtem Fortschlagen der Ventrikel, wurde am Säugethierherzen bei Vagusreizung beobachtet.

Ein wesentlicher Unterschied ist jedoch der, dass der Herzmuskel während der Kaliumwirkung für künstliche (mechanische oder elektrische) Reize je nach der Grösse der Dosis minder erregbar oder unerregbar wird und erst allmählich die Erregbarkeit wiedergewinnt, während auch bei starker Vagusreizung -- wenigstens am Ventrikel des Säugethierberzens - nie ein Schwinden der Erregbarkeit für künstliche Reize beobachtet wurde.

Da die Möglichkeit bestand, dass die Wirkung kleinerer K-Dosen auf Vagusreizung $\mathrm{zu}$ beziehen ist, wurden noch folgende Versuche gemacht.

Bei einem sonst intacten Kaninchen (Versuch Nr. 46 vom 1. Mai 1903) wurde der Blutdruck mittelst eines Manometers verzeichnet, der rechte Vagus durehschnitten und das Herzende desselben mittelst Stativelektroden faradisch gereizt. Die Reizschwelle für deutliche Verlangsamung der Herzaction Jag bei einem Rollenabstand

Ventrikels, der normale Beschaffenheit zeigte und sich scharf von den weissen Partien abgrenzte, sowie das rechte Herzrohr schwach fortschlugen. Die nähere Untersuchung des Herzens ergab, dass das Ostium der linken Coronararterie, welches fast doppelt so weit war als das der rechten, direct in der Richtung des Flüssigkeitsstromes offen lag, während das Ostium der rechten kleineren Coronararterie mehr seitlich an der Aortenwand sich befand. 
$($ R. - A. $)=18 \mathrm{~cm} . \quad$ (1 Grenet'sches Element, Du Bo i s'sches Schlitteninductorium.)

Hierauf wurde der Nerv zwischen der gereizten Stelle und dem Herzen in die mit $1 / 10 \mathrm{n}$. $\mathrm{KCl}$ - Lösung $(=0,74 \%$ ) gefullte Delle eines bohlen Objectträgers gelagert. Nach kurzer Zeit waren schon Reize von $19 \mathrm{~cm} \mathrm{R.-A.} \mathrm{wirksam,} \mathrm{nach} 1^{\prime}$ langer Einwirkung der $\mathrm{KCl}$-Lösung auf den Nerv (der inzwischen auch mittelst eines mit derselben KCl-Lösung befeuchteten Stückes Filtrirpapier bedeckt worden war) batte Vagusreizung schon bei $22 \mathrm{~cm} \mathrm{R.-A}$. deutlichen Erfolg. Nach längerer Finwirkung des $\mathrm{KCl}$ mussten aber wieder Reize bei R.-A. $=18 \mathrm{~cm}$, schliesslich bei R.-A. $=16 \mathrm{~cm}$ applicirt werden.

Hierauf wurde der Nerv auf dieselbe Art in $1 / 2$ n. $(=3,7 \%)$ $\mathrm{KCl}$-Lösung getaucht; die vorher angewendeten Reize wurden unwirksam, und nach drei Minuten waren dies auch Reize bei R.-A. $=0$. Als sodann der Vagus in physiologischer NaCl-Lösung abgespült und in derselben eingetaucht gelassen wurde, kehrte die Erregbarkeit wieder, die Reizschwelle lag dann bei R.-A. $=6 \mathrm{~cm}$.

Eine Wiederholung der Einbettung des Vagus in $1 / 2 \mathrm{n}$. KCl-Lösung brachte dasselbe Ergebniss: nach 85" waren Reize vom R.-A. $=0$ unwirksam, in $0,8 \%$ iger Kochsalzlösung trat Erholung ein (Reizschwelle $=6 \mathrm{~cm}$ R.-A.).

Ganz ähnlich verlief ein zweiter ebensolcher Versuch am Kaninchen (4. Mai 1903, Versuch Nr. 48). Hier lag die Reizschwelle des Vagus vor der $\mathrm{KCl}(1 / 10 \mathrm{n}$.) - Application bei 17,5, nach derselben bei $20,5 \mathrm{~cm} \mathrm{R}$.-A. Hierauf wurde der Nerv abgetupft, frei liegen gelassen und die rechte Jugularvene präparirt. Nach der Präparation lag die Reizschwelle für den Vagus bei R. $-A=17 \mathrm{~cm}$, war also wieder auf die frühere Grösse gesunken. Nun wurde $1 / 10 \mathrm{n}$. KCl-Lösung in die Jugularis injicirt, nach Injection von $1 \mathrm{cem}$ lag die Reizschwelle des Vagus bei 16,5 cm, nach weiterer Injection von $1 \mathrm{ccm}$ bei $17 \mathrm{~cm}$, als schliesslich noch $2 \mathrm{ccm}$ injicirt wurden, bei $20 \mathrm{~cm} \mathrm{R}$.-A.

Diese Versuche ergaben, dass Kalium in schwächerer Concentration, wenn es längere Zeit auf den Vagus einwirkt, Herabsetzung der Erregbarkeit, stärkere $\mathrm{KCl}-\mathrm{Lösung}$ auch völlige Aufhebung der Erregbarkeit bewirkt, die nach Entfernung des Giftes allmäblich bis zu einem gewissen Grade wiederkehrt.

Im Beginn der Einwirkung der sebwächeren (1/10 n.) Lösung von $\mathrm{KCl}$ auf den Vagus wurde eine vorübergehende Erhöhung der Er- 
regbarkeit des Vagus wahrgenommen, ebenso auch bei intravenöser Injection von geringen $\mathrm{K}$-Mengen. Eine directe Reizwirkung des Kaliums auf den Vagus wurde aber nicht beobachtet.

Wir fanden also ausser der äusseren Aehnlichkeit zwischen dem Ablauf der Kaliumwirkung und dem einer Vagusreizung - welche sich, wie schon oben erwähnt, durch die Unerregbarkeit der Muskulatur bei grösseren K-Dosen wesentlich unterscheiden - keinen Anhaltspunkt dafür, dass die Kaliumwirkung auf einer intracardialen Vagusreizung beruhe. -

Die Muscarinwirkung wich in unseren Versuchen von der des Kaliums in folgender Hinsicht ab. Injicirte man in das mit Ringer scher Lösung durchspülte Herz 1-2 ecm $0,1 \%$ ige Atropinlösung, so war Muscarin längere Zeit unwirksam, während Kalium prompt Verkleinerung und Verlangsamung der Contractionen, eventuell Herzstillstand hervorruft. Ferner ist beim Muscarinstillstand das Herz für künstliche Reize erregbar.

Calcium. Das Calciumchlorid bewirkte immer eine Verstärkung der Herzthätigkeit, eine Zunahme der Contractionsgrösse, wobei die Diastole oft weniger vollkommen wurde. Bei grossen Dosen war die systolische Zusammenziehung sehr kräftig und an den Ventrikeln gewöhnlich deutlicher ausgeprägt als an den Vorhöfen (Fig: 4 Taf. II). Auch nach Abtrennung der Vorhöfe am Kammerpräparat - trat nach Calciuminjection Verstärkung der Contractionen auf.

Neben der Vergrösserung der Pulshöhe trat bei vielen Injectionsversuchen - in allen Fällen, wenn die Wirkung stärker war, eine Zunahme der Frequenz auf. Bei schwächerer Wirkung auf die Contractionsgrösse war auch die Beschleunigung geringer, bisweilen blieb die Frequenz constant, niemals trat Verlangsamung auf.

Bemerkt sei noch, dass eine auf der Höhe einer Calciumwirkung vorgenommene Vagusreizung prompt kurzdauernden Stillstand herbeifübrte.

In der nachfolgenden Tabelle sind aus den zahlreichen Versuchen von Calciuminjectionen einige zusammengestellt. Injicirt wurde immer ${ }^{1 / 10} \mathrm{n} .=1,01 \%$ ige Lösung von $\mathrm{CaCl}_{2}$ in destillirtem Wasser.

In dem, Fig. 6 Taf. II wiedergegebenen Versuche schlug der Ventrikel im Alternans; nach der Injection von $3 \mathrm{ccm} 1 / 10 \mathrm{n} . \mathrm{CaCl}_{2}$ nahmen die grösseren Ventrikelcontractionen von $13^{1 / 2}$ bis $22^{1 / 2} \mathrm{~mm}$ $\mathrm{zu}$, während die kleineren von $b$ auf $20 \mathrm{~mm}$ anstiegen, so dass der 
Tabelle $I^{1}$ ).

\begin{tabular}{|c|c|c|c|c|c|c|c|}
\hline 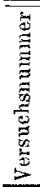 & Datum & $\begin{array}{c}\text { Versuchs- } \\
\text { thier }\end{array}$ & 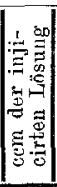 & $\begin{array}{c}\text { Aenderung der } \\
\text { Contractionsgrösse } \\
\mathrm{mm}\end{array}$ & $\begin{array}{c}\text { Aenderung } \\
\text { der } \\
\text { Schlagfrequenz } \\
\text { in } 5 \text { Sec. }\end{array}$ & $\left|\begin{array}{c}\text { Dieselbe } \\
\text { berechnet auf } \\
1 \text { Min. }\end{array}\right|$ & $\begin{array}{l}\text { Anmer- } \\
\text { kungen }\end{array}$ \\
\hline $\begin{array}{r}73 \\
89 \\
5 \\
11 \\
22 \\
65 \\
64\end{array}$ & $\begin{array}{l}\text { 28. Febr. } \\
\text { 5. März } \\
\text { 26. Mai } \\
\text { 12. Juni } \\
\text { 6. Juli } \\
\text { 9. Febr. } \\
\text { 18. Febr. } \\
\text { 16. März } \\
\text { 27. Mai } \\
\text { 97. " } \\
\text { 27. " } \\
\text { 28. " }\end{array}$ & $\begin{array}{c}\text { Hund } \\
" \\
" \\
" \\
" \\
\text { Katze } \\
\text { Kaninchen } \\
" \\
" \\
" \\
"\end{array}$ & $\begin{array}{l}3 \\
3 \\
2 \\
2 \\
4 \\
2 \\
2 \\
3 \\
2 \\
2 \\
2 \\
2\end{array}$ & 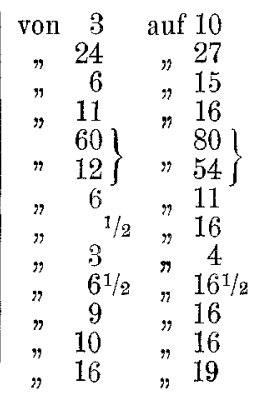 & 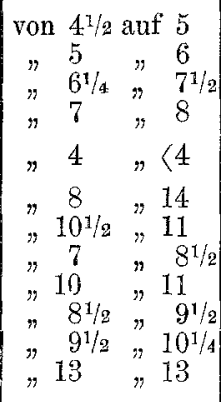 & 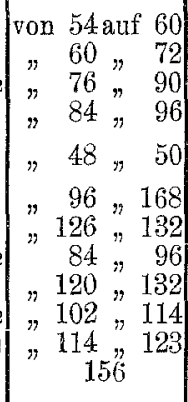 & $\begin{array}{l}\text { Alter- } \\
\text { nans } \\
\text { Termp. } \\
23^{1 /} / \mathbf{s}^{0}\end{array}$ \\
\hline
\end{tabular}

Alternans vorübergehend schwächer wurde. In anderen Fällen glich sich der Alternans durch Anwachsen der kleineren Contraction unter dem Einflusse der Ca-Wirkung ganz aus und schwand gänzlich oder kehrte nach Ablauf der Wirkung wieder.

Starke Ca-Dosen führen neben der Verstärkung und Beschleunigung auch zum Auftreten von Unregelmässigkeiten in Form von verfrüht auftretenden Systolen. Ferner wurde nicht zu selten im Anschlusse an grosse Ca-Dosen Flimmern des Herzens beobachtet.

Andererseits kann ein durch Ausfallen einzelner oder ganzer Gruppen von Ventrikelschlägen unregelmässig schlagendes Herz durch eine Ca-Injection bei gleichzeitiger Verstärkung und Beschleunigung zu regelmässigem Schlagen gebracht werden; nach einiger Zeit stellte sich dann gewöhnlich die Unregelmässigkeit wieder ein.

Injicirt man Calcium in ein in Flimmern gerathenes Herz, so werden die kleinen Flimmerbewegungen grösser: das Flimmern wird also dureh Calcium verstärkt.

Bei einem durch Kochsalzspülung stillstehenden Herzen wurden einmal nach Injection einer Ca-Menge eine Reihe von Contractionen beobachtet, worauf das Herz wieder still stand. Bei einigen Versuchen trat bei dem durch Muscarin zum Stillstande gekommenen

1) In den Tabellen ist der Druck und die Temperatur, die das Thermometer vor der Herzcanüle anzeigte, nicht angegeben, weil im Verlaufe einer Injectionswirkung wesentliche Aenderungen von Druck und Temperatur nicht vorkamen. 
Herzen das spontane Schlagen früher ein, wenn man Calcium injicirte; auch wurde die dureh Muscarin zu Stande gekommene Verlangsamung durch Ca-Injection behoben, das Herz schlug dann kräftiger und rascher.

Ferner wurde beobachtet, dass bei einem Herzen, dessen Ventrikel nach längerer Versuchsdauer keine deutlichen Ausschläge mehr verzeichneten, während die Vorhöfe sich kräftig contrahirten, eine Ca-Injection kräftige Ventrikelcontractionen auslöste. Stand das Herz nach langer Versuchsdauer gänzlich still, so sah man nach Application von Calcium die Curve, ohne dass Ausschläge verzeichnet wurden, bedeutend ansteigen, was auf eine systolische Zusammenziehung des Ventrikels hindeutet.

Gegensätzliche Wirkung von Kalium und Calcium. Die beschriebenen Wirkungen des Calciums zeigen einen directen Gegensatz zu den bei Kaliuminjection beobachteten; hier Verkleinerung und Verlangsamung der Contractionen bis zum völligen Stillstand in Diastole, mit nachfolgendem allmählichem Anwachsen der Contractionen, - beim Calcium Verstärkung (vorwiegend der Systole) und meist Beschleunigung.

Diese gegensätzliche Wirkung, die auch nach der zweiten, später noch zu besprechenden Methode nachweisbar ist, lässt sich auch durch gleichzeitige Injection von Kalium- und Calciumlösungen mittelst zweier Spritzen oder, noch präciser, durch Injection einer Mischung: bestimmter Mengen von $\mathrm{K}$ und $\mathrm{Ca}$ studiren. Dabei wurde so vorgegangen, dass zuerst eine bestimmte wirksame K-Dosis, dann eine bestimmte Ca-Dosis und hierauf - stets in solchen Intervallen, dass die Wirkungen wieder abgeklungen waren -, dieselben $\mathrm{K}$ - und Ca-Dosen gleichzeitig injicirt wurden. Da aber die vorausgegangenen Injectionen doch den Erfolg trüben konnten und genau gleichzeitige Injection mit zwei Spritzen, weil sie von zwei Personen besorgt werden inusste, schwer erzielbar war, wurden auch Mischungen v0] $\mathrm{Ca}$ und $\mathrm{K}$ in gewissen Verhältnissen hergestellt und hiervon verschiedene Mengen injicirt.

Hierbei zeigte es sich, dass die Salze in ihren Wirkungen einander derart beeinflussen, dass die abschwächende Wirkung des Kaliums durch die verstärkende des Calciums ganz oder zum Theii aufgehoben wurde. Die Art der Einwirkung ist von dem. Verhältnisse der Mischungszahlen, aber auch von der absoluten Menge jedes der beiden Salze abhängig. 
Wie z. B. Fig. $7 a, 7 b$ und 8, Taf. II zeigen, trat ein durch eine gewisse Menge Kalium allein ausgelöster Ventrikelstillstand auch auf, als man mit der gleichen $\mathrm{K}$-Menge eine (für sich allein ebenfalls deutlich wirksame) Ca-Dosis injicirte. Aber dieser Stillstand war dann kürzer als bei reiner K-Injection; ferner erfolgte bei letzterer in demselben Falle der Wiederbeginn der Herzaction nach dem Stillstand mit einer sebr grossen Contraction, der aber viel kleinere, erst allmählich an Grösse zunehmende Contractionen folgten, entsprechend der allmählichen Zunahme der Reactionsfähigkeit der Ventrikel nach Ablauf der reinen K-Wirkung. Bei gleichzeitiger Ca-Injection waren die Ausschläge nach dem Stillstand grösser als vorher und erfolgten auch in beschleunigtem Tempo, eine Folge der die Reactionsfähigkeit des Herzens steigernden Application des Calciums.

In anderen Fällen bewirkte das $\mathrm{K}$ bei Ca-Gegenwart zwar wie sonst Abschwächung und Verlangsamung (Fig. $12 a$ und $b$, Taf. III), aber die Wiederzunahme der Contractionen erfolgte viel rascher, und die Contractionen wurden viel grösser als vorher.

Mitunter überwog die verstärkende Wirkung des $\mathrm{Ca}$, und die Wirkung des $\mathrm{K}$ prägte sich dann in einer mässigen Verlangsamung der durch $\mathrm{Ca}$ verstärkten Contractionen (Fig. $12 c$, Taf. III) oder nur in Verkleinerung der ersten Contractionen aus (Fig. 11, Taf. III).

Die nachfolgende Tabelle II auf Seite 287 gibt Beispiele der antagonistischen Wirkung des Kaliums und Calciums in verschiedenen Versuchen.

Natriumbicarbonat. Das Natriumbicarbonat bewirkt bei seitlicher Injection eine Vergrösserung der Herzcontractionen, gewöhnlich ohne Veränderung der Schlagfrequenz, letztere bleibt meist constant, bisweilen tritt mit der Verstärkung auch eine geringfügige Verlangsamung ein.

In Fig. 18, Taf. IV ist eines der gewöhnlichen Bilder bei Injection von $\mathrm{NaHCO}_{3}(1 / 4 \mathrm{n}$. Lösung $=2,1 \%)$ abgebildet, die $\mathrm{Zu}-$ nahme betrifft gleichmässig Systole und Diastole. In diesem Falle erfolgte die Injection 15 Minuten nach Beginn der Durchspülung; die Wirkung war von relativ kurzer Dauer. An Herzen jedoch, welche schon längere Zeit, mit Ring er' scher Lösung gespeist, geschlagen hatten und schon kleine Ausschläge verzeichneten, beobachtet man eine besonders lange Nachwirkung der Natriumbicarbonat-Injection. Hier erzielt man mit kleinen Dosen von $\mathrm{NaHCO}_{3}$ eine beträchtliche 
T a b elle II.

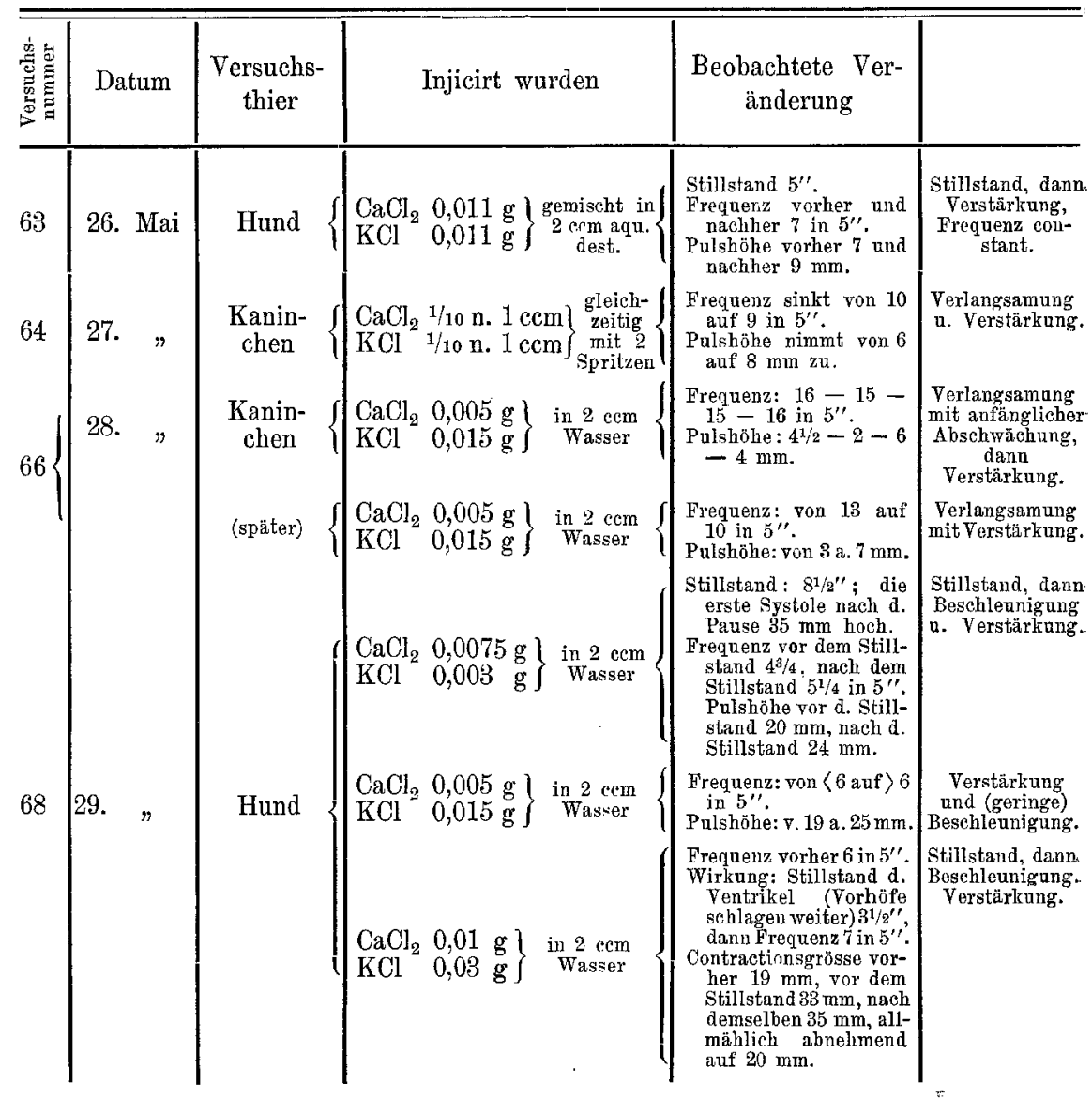

Verstärkung der Herzthätigkeit, die sehr lange andauert (s. Fig. 17 Taf. IV). Schon hierdurch unterscheidet sich die verstärkende Wirkung des $\mathrm{NaHCO}_{3}$ von der des Calciums, bei der wir ausserdem eine viel grössere Verstärkung der Systole und Beschleunigung der Herzaction beobachteten.

Ferner beseitigte $\mathrm{NaHCO}_{3}$ öfter Anomalien in der Herzthätigkeit; so wurde beobachtet, dass der Alternans nach $\mathrm{NaHCO}_{3}$-Injection verschwand, indem die kleinere Contraction stärker zunahm als die grössere (bisweilen kehrte er nachher wieder zurück); besonders. aber wurde bei Ausfallen einzelner oder mehrerer Ventrikelschläge durch $\mathrm{NaHCO}_{3}$-Injection die regelmässige Folge meist wieder hergestelit. 
Dieselben Wirkungen wie mit dem Natriumbicarbonat erhielten wir durch Injection von Natriumcarbonat und Natronlauge in entsprechend kleineren Dosen: Vergrösserung der Contractionen, langes Ueberdauern der Wirkung. Das Carbonat gibt sogar bisweilen auch in halb so grossen Dosen kräftigere Wirkungen als das Bicarbonat, und dasselbe kann von der Natronlauge gesagt werden. Von der Natronlauge dürfen nur sehr verdünnte Lösungen $(2-1 / 2 \mathrm{mg}$ auf $100 \mathrm{~g}$ Aqua) verwendet werden, da bei stärkeren auf die bedeutende Verstärkung leicht rasche Abnahme der Contractionen folgt. Dasselbe wurde auch bei Injection grösserer Mengen des $\mathrm{Na}_{2} \mathrm{CO}_{3}$, ja, auch des $\mathrm{NaHCO}_{3}$ beobachtet (siehe folgende Tabelle Versuch $\mathrm{Nr}$. 87: $7 \mathrm{ccm} \mathrm{NaHCO}_{3} \mathrm{1}_{4} \mathrm{n}$.), es kam hierbei neben Abschwächung der Herzthätigkeit auch zu Unregelmässigkeiten in Form von Ausfallen einzelner, oder regelmässig jeder zweiten Ventrikelsystole; neuerliche Injection von $\mathrm{NaHCO}_{s}(2 \mathrm{ccm} 1 / 4 \mathrm{n}$.) beseitigte in diesem Falle die Unregelmässigkeit, dieselbe kehrte aber wieder.

Im Hinblicke auf die erwähnten Besonderheiten der Wirkung des Natriumbicarbonats und Natriumearbonats seien einige Versuche im Auszug angeführt. In folgender Tabelle III anf Seite 289 ist im vierten Stabe die vom Beginne der Durchspülung des Herzens mit Ring er'scher Lösung bis zur Injection verstrichene Zeit angegeben.

Kochsalz. Injicirt man Kochsalz in so geringen Mengen wie die vorgenannten Salze, so bemerkt man keine Aenderung der Herzcontractionen, erst bei stärkeren Dosen beobachtet man eine Wirkung. auf das Herz.

Dieselbe besteht in einer ziemlich rasch auftretenden bedeutenden Abnahme der Contractionen, die dann allmäblich zur normalen Höhe zurückkehren (s. Fig. 5 Taf. II und Fig. 13 Taf. III). Bei grösseren Dosen kam es vorübergehenơ dazu, dass keine merkbaren Ausschläge verzeichnet wurden (z. B. bei Injection von $10 \mathrm{ccm} \mathrm{n.=}$ $5,8 \% \mathrm{NaCl}$-Lösung). Im Gegensatz zum Kalium, von dem wenige Kubikcentimeter einer $0,74 \%$ igen Lösung genügten, um einen prompten Stillstand hervorzurufen, das also eine specifische Giftwirkung entfaltet, mussten von $\mathrm{NaCl}$ sehr starke Concentrationen genommen werden, um eine Aenderung der Herzthätigkeit zu erhalten; diese wird wohl schon dureh Aenderung des Wassergehaltes der Gewebe bewirkt, und in der That sieht man nach Injection grosser NaCl-Dosen eine schwere Schädigung des Herzens; so beobachteten wir einmal nach Injection einer concentrirten 
T a belle III.

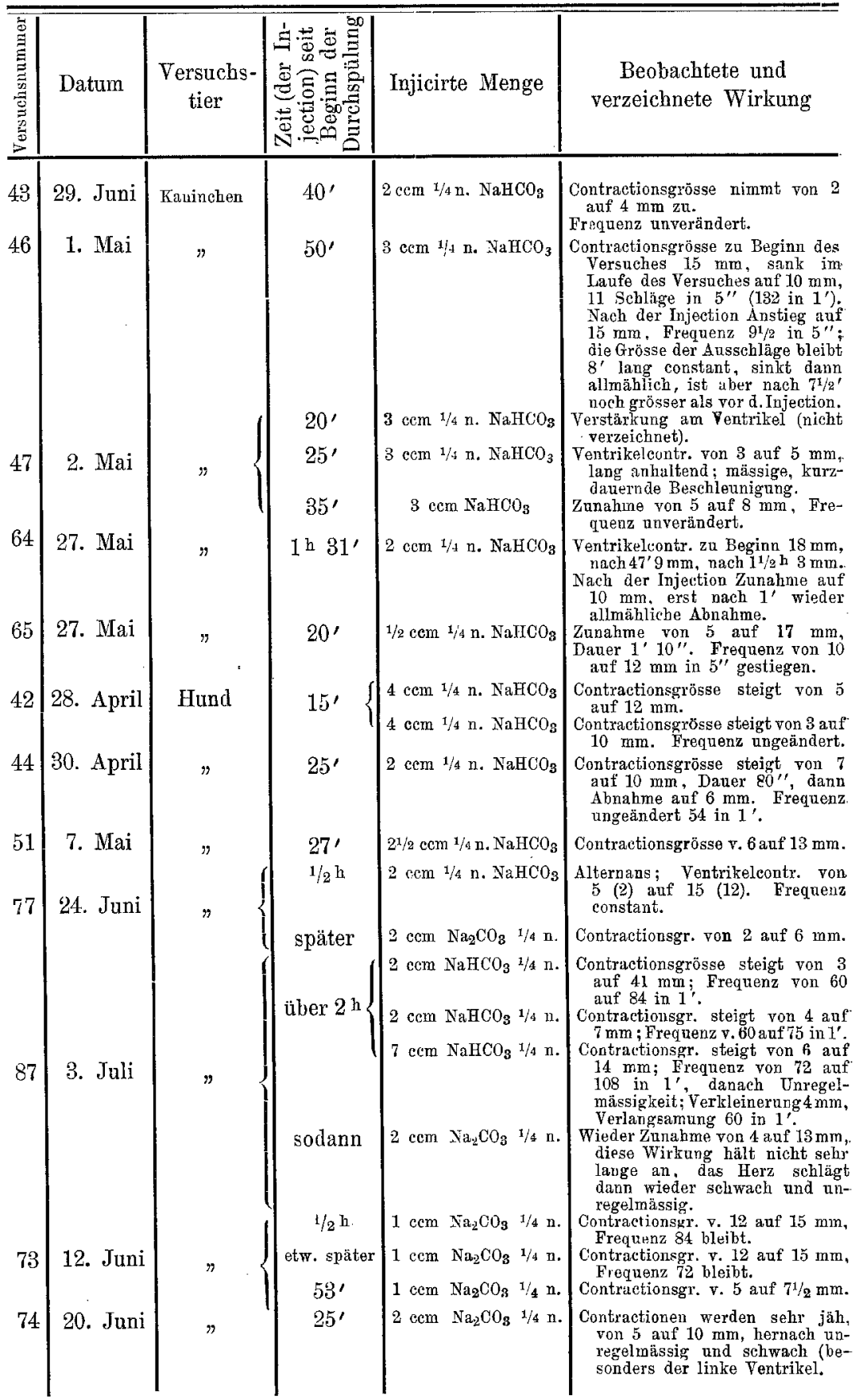


Kochsalzlösung in's Herz sofortigen Stillstand, das ganze Herz wurde hart, weisslich, glänzend, doch begann es nach längerer Durchströmung wieder ganz schwach zu schlagen.

Die Tabelle IV gibt die Erfolge einiger Kochsalzinjectionen wieder.

Tabelle IV.

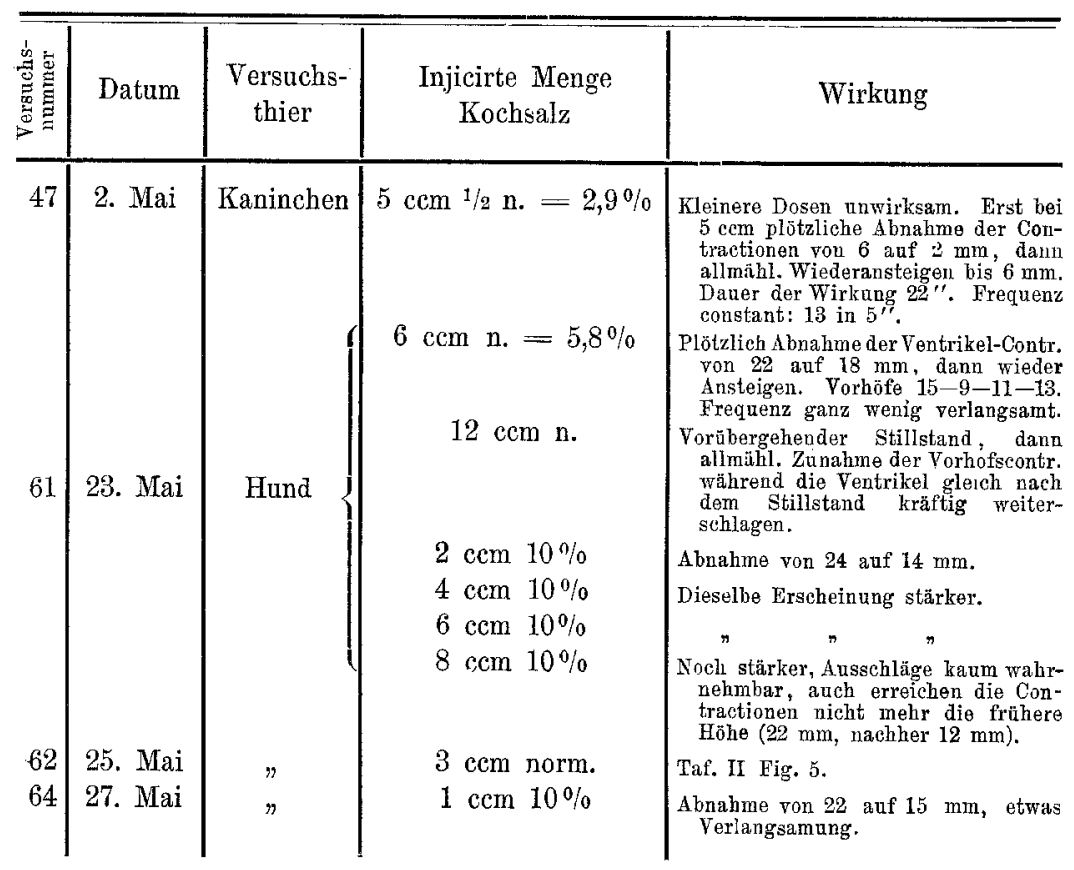

Ergebnisse der Versuche nach der zweiten Methode.

a) Weglassen eines Bestandtheiles der Ringer'schen Lösung.

Ringer-Lösung ohne Calcium. Lässt man in das isolirte, mit der Ring er'schen Lösung wiederbelebte Herz Ring e r-Lösung ohne Calcium einströmen, so nehmen die Herzcontractionen und die Frequenz allmählich ab; wenn dies eine Zeit lang fortgesetzt wird, hören die Ventrikel auf sich zu contrahiren, während die Vorhöfe noch weiter schlagen, bis schliesslich das ganze Herz stillsteht.

Lässt man wieder Ringer'sche Lösung in der gewöhnlichen Zusammensetzung durchfliessen, so erholt sich das Herz wieder und 
kann wieder zur früheren Höhe der Ausschläge und Frequenz gelangen, ja sie um ein Geringes übertreffen.

Die beschriebene Veränderung der Herzaction vollzieht sich allmählich (siehe Fig. 16 Tafel IV), ebenso die Rückkehr zur früheren Stärke bei neuerlicher Durchströmung des Herzens mit gewöhnlicher Ringer'scher Lösung; die Herzaction bleibt dabei regelmässig. Neben dem Wegfall des Calciums, der an sich die Ringer-Lösung zur Erhaltung der Herzthätigkeit unfähig macht, kommt bei dieser Art des Versuches auch noch die abschwächende Wirkung des Kaliums zur Geltung, die bei Fehlen des Calciums unbeeinflusst von diesem und daher stärker ist.

Die Zeit, in der die Abschwächung der Herzthätigkeit vor sich geht, ist verschieden; so war in einem Falle (Hund) die Höhe der Contractionen schon nach einer Minute von 21 auf $3 \mathrm{~mm}$ gesunken, Durchleitung von Ringer'scher Lösung hob sie wieder auf $22^{1 / 2} \mathrm{~mm}$. In einem anderen Versuche (Hund) war nach $4^{\prime} 20^{\prime \prime}$ die Höhe von $22 \mathrm{~mm}$ auf $5 \mathrm{~mm}$ herabgegangen; als nun $2 \mathrm{ccm}^{1 / 10} \mathrm{n}$. CaCl-Lösung seitlich injicirt wurden, nahmen die Contractionen stark an Grösse zu (bis $40 \mathrm{~mm}$ ), doch ging diese Verstärkung rasch vorüber, indem die Contractionsgrösse wieder auf die Höhe vor der Injection sank.

Ringer-Lösung ohne Kalium. Ganz anders gestaltet sich das Bild bei Durchspülung mit . K-freier Ring er-Lösung. Die Contractionsgrösse nimmt bedeutend zu, die Frequenz steigt gewöhnlich beträchtlich an. Besonders kräftig und jäh ist die $\mathrm{Zu}-$ sammenziehung der Ventrikel, aber auch die Vorhöfe zeigen eine bedeutende Verstärkung der Contractionen. Leitet man nach einer nicht zu langen Zeit wieder normale Ringer'sche Lösung in's Herz, so nehmen die Contractionen und die Frequenz allmählich wieder $a b$, bis beide die frühere Grösse gänzlich oder nahezu erreicht haben. (Fig. 14 Taf. III.)

Wie beträchtlich die Wirkung einer K-freien Ringer-Lösung ist, mögen einige Zahlen zeigen:

20. Mai. Hund: Zunahme der Contractionsgrösse von 10 auf $27 \mathrm{~mm}$, der Frequenz von 66 auf 84 Schläge in $1^{\prime}$.

9. Mai. Hund (Alternans): Zunahme der Contractionsgrösse von 32 auf $51 \mathrm{~mm}$, Frequenz constant.

9. Mai. Hund (Alternans): Zunahme der Contractionsgrösse von 22 auf $50 \mathrm{~mm}$, Frequenz constant.

27. Juni. Hund (Alternans): Zunahme der Contractionsgrösse von 21 auf $35 \mathrm{~mm}$, Frequenz constant 52 in $1^{\prime}$. 
27. Juni. Hund (Alternans): Zunahme der Contractionsgrösse von 18 auf $33 \mathrm{~mm}$, Frequenz constant 52 in $1^{\prime}$.

9. Juni. Hund: Zunahme der Contractionsgrösse von 25 auf $47 \mathrm{~mm}$, der Frequenz von 21 auf 60 Schläge in $1^{\prime}$.

19. Mai. Hund: Zunahme der Contractionsgrösse von 17 auf $61 \mathrm{~mm}$, der Frequenz von 51 auf 69 Schläge in $1^{\prime}$.

Hinsichtlich der Frequenzänderung muss bemerkt werden, dass sich dieselbe gewöhnlich bei längerer Durchströmung mit $\mathrm{K}$-freier Ring e r-Lösung stärker ausprägte.

Die im Versuche vom 9. Juni beobachtete bedeutende Frequenzerhöhung (von 21 auf 60 ) bezieht sich nur auf die Ventrikel, welche bei Durchströmung mit der normalen Ringer'schen Lösung nur jeden zweiten Vorhofsschlag mit einer Contraction beantwortet hatten; diese Anomalie schwand bei der Einströmung K-freier Speisungsflüssigkeit, ausserdem trat auch Beschleunigung ein.

Auch der Alternans wird bei Durchströmung mit dieser Lösung geändert, indem die kleinere Contraction mehr an Grösse zunimmit als die grössere und diese ganz oder fast an Höhe erreicht.

Dauert die Durchströmung mit der K-freien Ringer-Lösung lange an, so kommt es allmählich zu einer Abnahme der Contractionen. In einigen Versuchen kam es auf der Höhe der $\mathrm{Zu}$ nahme zu Unregelmässigkeiten in Form von verfrühten Systolen der Ventrikel; mit der dann erfolgenden Abnahme der Contractionen traten bisweilen auch Störungen in der Form auf, dass die Ventrikel nicht mehr auf jeden Vorhofsschlag antworteter; schliesslich standen die Kammern still, während die Vorhöfe weiterschlugen; in diesem Stadium kam es erst nach längerer Durchströmung mit normaler Ringer'scher Lösung zur Wiedererholung des Herzens, so dass dasselbe rhythmische Thätigkeit von mittlerer Stärke wiedererlangte; in anderen Fällen blieb die Herzthätigkeit auch dann schwach, und das zeitweilige Aussetzen der Ventrikel blieb bestehen. -

Die Erscheinungen nach Durchströmung K-freier RingerLösung entsprechen den bei Erhöhung des Calciumgehaltes durch seitliche Injection beobachteten; da aber der Ca-Gehalt der K-freien Ring e r-Lösung nicht geändert wurde, ist im Hinblick auf das beobachtete antagonistische Verhalten von Kalium und Calcium anzunehmen, dass wir es beim Fehlen des Kaliums mit einer uncompensirten Calciumwirkung zu thun haben. - 
Ringer-Lösung ohne $\mathrm{NaCl}$. Diese wurde nur in einem Versuche zur Durchströmung verwendet, es ergab sich, wie zu erwarten stand, bei der hochgradigen Herabsetzung des Salzgehaltes ein rasches Erlahmen des Herzens; zuerst hörten die Contractionen der Ventrikel auf, dann die der Vorböfe, das Herz wurde starr, weisslich und bei Wiederdurchströmen des Herzens mit normaler Ringer'scher Lösung kam es nicht mehr zu einer Thätigkeit der Kammern, während die Vorhöfe einige Zeit schwache Ausschläge zeigten.

Ringer-Lösung ohne Natriumbicarbonat. Wurde aus der Ringer'schen Lösung das Natriumbicarbonat weggelassen, so nahm die Stärke der Herzthätigkeit allmählich ab, die Frequenz blieb meist ungeändert oder nahm etwas ab. (Fig. 19 Taf. IV.) Bei Wiederdurchströmung mit normaler Ringer'seher Lösung stieg die Grösse der Contractionen wieder auf die frühere Höhe, auch die Frequenz nahm wieder zu.

Die Abnahme der Contractionen ging bei den verschiedenen Versuchsherzen verschieden rasch vor sich; im Nachfolgenden seien aus den Versuchsprotokollen einige Daten wiedergegeben.

\section{Juli. Versuch Nr. 85; Hund.}

Bei normaler Ringer-Lösung Contractionsgrösse (am Ventrikel) 141/2 mm $\left(9\right.$ in $5^{\prime \prime}$ ), nach $21 / 2^{\prime}$ langer Durchspülung mit Ringer-Lösung ohne $\mathrm{NaHCO}_{3}$ $12 \mathrm{~mm}\left(8^{8 / 4}\right.$ in $\left.5^{\prime \prime}\right)$, nach weiteren $4^{1 / 2^{\prime}} 5 \mathrm{~mm}$ (7 in $\left.5^{\prime \prime}\right)$, hierauf Wiederdurchströmung mit normaler Ringer-Lösung nach 1' 40 " Contractionsgrösse $12 \mathrm{~mm}$; nach 51/2" $15 \mathrm{~mm}\left(8\right.$ in $\left.5^{\prime \prime}\right)$.

\section{Juli. Versuch Nr. 84; Kaninchen.}

Contractionsgrösse anfangs bei normaler Ringer-Lösung $10 \mathrm{~mm}$ (Frequenz 19 in $5^{\prime \prime}$ ), nach $8^{1 / 4^{\prime}}$ dauernder Durchströmung mit Ringer-Lösung ohne $\mathrm{NaHCO}_{3}$ $2 \mathrm{~mm}$, Frequenz 13 in 5", hierauf wieder normale Ring er-Lösung, nach $3^{\prime} 7 \mathrm{~mm}$, Frequenz 13 in $5 "$.

\section{Juni. Versuch Nr. 77; Hund.}

In diesem Falle, in welchem das Herz nach mehreren Durchströmungsversuchen sehr schlecht schlug, nahm die Herzthätigkeit nach $1^{3 / 4^{\prime}}$ Ianger Durchströmung mit Ringer-Lösung ohne $\mathrm{NaHCO}_{3}$ von $7 \mathrm{~mm}$ Contractionsgrösse an den Ventrikeln ( $8 \mathrm{~mm}$ an den Vorböfen) bis zum Verschwinden der Ventrikelpulse an der Curve ab, während die Vorhöfe schwächer $(3 \mathrm{~mm})$ und langsamer (vorher 7, dann 4 in $5 "$; Temp. war nur um $1 / 2^{0}$ gesunken) weiterschlugen. Den weiteren Verlauf des Versuches siehe später (Seite 300).

Injicirt man während der durch den Mangel an $\mathrm{NaHCO}_{3}$ entstandenen Abnahme der Herzthätigkeit seitlich (in der gewöhnlich verwendeten Dosis) Natriumbicarbonat, Natriumearbonat oder Natron-

E. Pflüger, Archiv für Physiologie. Bd, 99. 
lauge, so nimmt die Höhe der Contractionen wieder oft bedeutend an Grösse zu und erst nach längerer Zeit wieder ab. Dasselbe Ergebniss bekamen wir unter den genannten Verhältnissen auch nach Injection von 10-12 ecm einer Ring er-Lösung, die entweder mit $\mathrm{NaHCO}_{3}$ oder $\mathrm{Na}_{2} \mathrm{CO}_{3}$ oder $\mathrm{NaOH}$ alkalisch gemacht worden war, wobei die Grösse der Zunahme je nach der Dosis und dem Zustande des Herzens verschieden war.

\section{Mai. Versuch Nr. 60; Hund.}

(Siehe Fig. 19 Taf. IV) Contractionsgrösse anfangs $15 \mathrm{~mm}$ (r. Ventrikel) Frequenz 6 in $5^{\prime \prime} ; \mathrm{NaHCO}_{3}$ freie Ringer-Lösung, nach $3^{\prime}$ C. G., $5^{1 / 2} \mathrm{~mm}\left(5^{1 / 2}\right.$ in $\left.5^{\prime \prime}\right)$, nach 50" Injection von $2 \mathrm{ccm}^{1 / 4} \mathrm{n}$. NaHCO${ }_{3}$-Lösung: C.G., $17 \mathrm{~mm}\left(5^{1 / 2}\right.$ in 5"), nach $50 " 5 \mathrm{~mm}$, nach $1^{\prime} 3 \mathrm{~mm}$, hierauf normale Ringer-Lösung: $4 \mathrm{~mm}$, Injection von $2 \mathrm{ccm} \mathrm{NaHCO}_{3} 1 / 4$ n. $12 \mathrm{~mm}$ (Frequenz blieb 5//2 in $5^{\prime \prime}$ ).

\section{Juni. Versuch Nr. 82; Hund.}

Anfangs bei Ring er-Lösung Ventr. (V.) $8 \mathrm{~mm}$, Vorh. (A.) $16 \mathrm{~mm}$, Frequenz 6 in 5". Temp. $30^{\circ}$. - Durchströmung mit Ringer-Lösung ohne $\mathrm{NaHCO}_{3}$ : nach $7^{\prime}$ V. $3 \mathrm{~mm}$, A. $6 \mathrm{~mm}$, Frequenz 5 in $5^{\prime \prime}$. Temp. $30,5^{\circ}$. - Injection von $2 \mathrm{ccm} 1 / 4 \mathrm{n} . \mathrm{Na}_{2} \mathrm{CO}_{3}$ : V. $5 \mathrm{~mm}$, A. $15 \mathrm{~mm}$; nach 1' V. $4 \mathrm{~mm}$, A. $15 \mathrm{~mm}$; nach $2^{1 / 2^{\prime}}$ V. $3 \mathrm{~mm}$, A. $6 \mathrm{~mm}$. Injection $12 \mathrm{ccm}$ norm. Ringer-Lösung (mit $\mathrm{NaHCO}_{3}$ $0,03 \%$ alkalisirt): V. $3^{1 / 2} \mathrm{~mm}$, A. $9 \mathrm{~mm}$; nach $1 / 2^{\prime}$ V. $2 \mathrm{~mm}$, A. $7 \mathrm{~mm}$; nach $1^{3 / 4^{\prime}}$ V. $1^{1 / 2} \mathrm{~mm}$, A. $5 \mathrm{~mm}$. - Injection $12 \mathrm{ccm} \mathrm{Ringer-Lösung} \mathrm{alkalisirt} \mathrm{mit} \mathrm{Na}_{2} \mathrm{CO}_{3}$ $(0,002 \%)$ : V. $3 \mathrm{~mm}$, A. $8 \mathrm{~mm}$; nach $40^{\prime \prime}$ V. $2 \mathrm{~mm}$, A. $5 \mathrm{~mm}$; nach $1^{\prime}$ V. $1^{1 / 2} \mathrm{~mm}$, A. $4 \mathrm{~mm}$. - Injection $12 \mathrm{ccm} \mathrm{Ring}$ e r-Lösung alkalisirt mit $\mathrm{NaOH}(0,0005 \%)$ : V. $2 \mathrm{~mm}$, A. $5 \mathrm{~mm}$. - Hierauf wurde das Herz wieder mit norm. RingerLösung durchströmt, ganz allmählich erfolgte Zunahme der Contractionsgrösse, nach $1^{1 / 2}$, V. $2^{1 / 2} \mathrm{~mm}$, A. $5 \mathrm{~mm}$, Herzthätigkeit schwach.

Es hatte in diesem Falle die Herzthätigkeit unter dem Einflusse der beständig im ganzen durchfliessenden $\mathrm{NaHCO}_{3}$-freien Ringer-Lösung allmählich immer mehr abgenommen, auch als dann normale Ringer'sche Lösung durchströmt wurde, trat keine rechte Erholung mehr ein.

Nur bei zwei Herzen unterschied sich der Ablauf der Wirkung der $\mathrm{NaHCO}_{3}$-freien Ring er - Lösung vollständig von den bisher mitgetheilten Versuchen. Während bei diesen die Abnahme der Contractionen allmählich erfolgt war, kam es bei zwei Hundeherzen zu einer plötzlichen Unterbrechung der Herzthätigkeit.

Im ersten Versuche (9. Mai. Versuch Nr. 54 ; Hund) schlug das Herz bei Ringer'scher Lösung im Alternans, Contractionsgrösse am Ventrikel 47 (42) mm, Frequenz $7 \frac{1}{2}$ in 5 ". Unmittelbar nach Durchleitung der $\mathrm{NaHCO}_{3}$-freien Ring er Lösung sank die Höhe plötzlich auf $12 \mathrm{~mm}$, die Ventrikelschläge erfolgten seltener als die der Vorhöfe (Ausfallen von 1, 2--6 Ventrikelschlägen) und waren kaum halb so gross als die vorhergehenden, die Vorhöfe schlugen schwach weiter. Nach 
1 ' wurde wieder normale Ringer'sche Lösung durchströmt, die Ventrikel folgten bald jedem zweiten, dann jedem Vorhofschlage, die Höhe stieg wieder auf $32(22) \mathrm{mm},(7$ in $5 "$ ).

In Versuch Nr. 59 (20. Mai; Hund) folgte dem Wechsel von der normalen zur alkalifreien Ringer-Lösung zuerst eine geringe Zunahme der Ventrikelcontractionen von 11 auf $13^{1 / 2} \mathrm{~mm}$ (eine sonst nie beobachtete Erscheinung), dann Abnahme auf $10 \mathrm{~mm}$, hierauf Stillstand der Ventrikel (Vorhöfe wurden diesmal nicht verzeichnet), nach 29 " erfolgte eine kräftige Ventrikelcontraction, hierauf wurde normale Ringer-Lösung durchströmt, der Stillstand dauerte noch 30", dann kam es zu regelmässigem Schlagen, die Contrationshöhe betrug zuerst $5 \mathrm{~mm}$ und stieg allmäblich bis $11 \mathrm{~mm}$.

Der Grund für dieses von den übrigen Versuchen abweichende Verhalten (Versuchsfehler?) ist uns nicht bekannt geworden.

b) Weglassen zweier (bezw. dreier) Bestandtheile der Ringer'schen Lösung.

Es war von Interesse, den Einfluss von Lösungen kennen zu lernen, die ausser dem Kochsalz nur noch einen der anderen Bestandtheile der Ringer'schen Lösung in derselben procentischen Menge wie in dieser enthielten.

Von der Verwendung einer nur Kochsalz und Kalium enthaltenden Lösung wurde mit Rücksicht auf die bekannte abschwächende Wirkung des letzteren abgesehen, der Verlauf dürfte dem mit Kfreier Ring er - Lösung entsprechen, nur mit Rücksicht darauf, dass auch das Natriumbicarbonat fehlt, entsprechend rapider zur Abnahme bezw. Aufhebung der Herzaction führen.

Ringer-Lösung ohne $\mathrm{KCl}$ und ohne $\mathrm{CaCl}_{2}$ (enthält nur $\mathrm{NaCl}$ und $\mathrm{NaHCO}_{3}$ ). Bezüglich der Combination: Kochsalz und Natriumbicarbonat, liegt für das isolirte Säugethierherz bereits eine Untersuchung von $\mathrm{R} \mathrm{u} \mathrm{s} \mathrm{ch} \mathrm{(32)} \mathrm{vor,} \mathrm{der} \mathrm{fand,} \mathrm{dass} \mathrm{das}$ durch reine Kochsalzlösung zum Stillstand gebrachte Herz mit einer alkalischen $\left(0,01 \% \mathrm{NaHCO}_{3}\right.$ enthaltenden) Kochsalzlösung zum regelmässigen und kräftigen Schlagen gelangte, dass aber die Pulshöhen kleiner sind und viel rascher abfallen als bei Durchströmung mit Ringer'scher Lösung. Die letztere Beobachtung konnte ich bestätigen, nur ging ich bei den Versuchen umgekehrt vor.

So sah ich in Versuch Nr. 59 vom 20. Mai (Hund), die bei Durchströmung mit Ringer'scher Lösung $10 \mathrm{~mm}$ messenden Ventrikelconcentrationen nach $1^{\prime}$ dauernder Durchströmung mit einer $0,03^{\circ} \%$ $\mathrm{NaHCO}_{3}$ enthaltenden $1 \%$ igen Kochsalzlösung auf $5 \mathrm{~mm}$, nach weiteren 
$40^{\prime \prime}$ auf $2 \mathrm{~mm}$ sinken, hierauf bei Durehströmung mit $R$ ing e $r$ 'scher Lösung wieder zur früheren Höhe zunehmen.

Ausfübrlicher sei folgender, auch in anderer Beziehung bemerkenswerther Versuch vom 4. Juli (Nr. 88; Hund) mitgetheilt. Hier betrug 10 Minuten nach Beginn der Durchströmung die Grösse der Ventrikelschläge $14 \mathrm{~mm}$, die der Vorhöfe $36 \mathrm{~mm}$.

Als hierauf $\mathrm{NaHCO}_{3}$ enthaltende Kochsalzlösung durchströmte, trat folgender Verlauf ein:

$\begin{array}{cccc}\text { Contractionsgrösse } & \text { Ventrikel } & \text { Vorhof } & \text { Frequenz in 5 Sec. } \\ \text { nach } 20 \text { Sec. } & 10 & 23 & 5^{3 / 4} \\ " 10 " & 5^{1 / 2} & 4 & 5^{1 / 2} \\ " 10 " & 3 & 2 & 4^{1 / 2}\end{array}$

Nach weiteren 30 Secunden waren die Ausschläge schon so schwach, dass sie nicht mehr verzeichnet wurden, blieben aber regelmässig.

Hierauf wurde K-freie Ring e r-Lösung durchgeleitet, sehr bald (nach 20") traten an Grösse rasch zunehmende und die Contractionen zu Beginn des Versuches überragende Contractionen (Ventrikel $=38 \mathrm{~mm}$ ) auf, welche aber durch das Vorkommen verfrüht auftretender Systolen der Ventrikel eine Störung im Rhythmus zeigten. Es wurde sodann nach ca. 1 Minute normale Ringer'sche Lösung umgeschaltet, die Contractionen wurden regelmässig, ihre Grösse nahm bis $14^{1 / 2} \mathrm{~mm}$ und schliesslich $8 \mathrm{~mm}$ am Ventrikel ab.

Nach einiger Zeit (22 Minuten seit Beginn des ganzen Versuches) wurde statt der normalen Ringer'schen Lösung calciumfreie Ringer Lösung durchströmt, die Ausschläge nahmen nach 1 Minute von 6 auf $3 \mathrm{~mm}$ (V.) bezw. von 23 auf $17 \mathrm{~mm}$ (A.) ab, nach 10 Sekunden betrug V. $21 / 2, A .6 \mathrm{~mm}$, und nach weiteren 20 Sekunden wurden die Contractionen nicht mehr verzeichnet. Als nun normale Ring er'sche Lösung durchströmt wurde, dauerte es noch 1 Minute, bis merkliche Ausschläge verzeichnet wurden, nach 1/2 Minute betrugen die Contractionen am Ventrikel $2^{1 / 2} \mathrm{~mm}$, am Vorhofe $6 \mathrm{~mm}$, nach einer weiteren Minute am Vorbofe $20 \mathrm{~mm}$, während die Ventrikel nicht mehr als $2^{1 / 2} \mathrm{~mm}$ hohe Ausschläge verzeichneten, obwohl sie kräftig schlugen.

Wir sahen demgemäss durch eine Lösung, der das $K$ fehlte, die Wiedererholung eines vorher nur mit $\mathrm{NaCl}$ und $\mathrm{NaHCO}_{3}$ durehströmten Herzens nach bedeutender Abnahme der Thätigkeit viel rascher auftreten als bei dem in Folge Calciummangels ebenso 
schlecht schlagenden Herzen nach Durchleitung normaler (also auch K enthaltender) Ringer'scher Lösung.

Ringer-Lösung ohne $\mathrm{KCl}$ und $\mathrm{NaHCO}_{3}$ (enthält nur $\mathrm{NaCl}$ und $\mathrm{CaCl}_{2}$ ). Bei Durchfluss einer Kochsalz und Calciumchlorid enthaltenden Lösung tritt eine Verstärkung der Contractionen mit Zunahme der Frequenz auf.

Nach der anfänglichen Zunahme der Contractionsgrösse kommt es bei Durchströmung mit $\mathrm{NaCl}+\mathrm{CaCl}_{2}$ zu einer Abnahme derselben, wie folgende Beispiele zeigen:

\section{Mai. Versuch Nr. 59; Hund.}

Bei normaler Ring er-Lösung Ventrikelcontractionen $13 \mathrm{~mm}$ (Frequenz $3^{1 / 2}$ in 5", Temp. $30^{\circ}$ ) nach $50^{\prime \prime}$ Durchströmung mit $\mathrm{NaCl}+\mathrm{CaCl}_{2} 17 \mathrm{~mm}$ (4 in $5^{\prime \prime}$ ), nach weiteren $2^{1 / 2} / 23 \mathrm{~mm}\left(4^{1 / 2}\right.$ in $\left.5 "\right)$, Auftreten vereinzelter verfrühter Systolen. Hierauf constante Abnahme bis $5 \mathrm{~mm}\left(3\right.$ in $\left.5^{\prime \prime}\right)$. Jetzt normale Ringer'sche Lösung: Erholung nach 3' auf $10 \mathrm{~mm}$ (3 in 5", Temp. $29^{\circ}$ ).

\section{Juli. Versuch Nr. 87; Hund.}

Contractionsgrösse bei normaler Ring er-Lösung $15 \mathrm{~mm}$ (Frequenz $6^{1 / 1} / 2$ in $5^{\prime \prime)}$. Nach $11^{1 / 2}$ ' dauernder Durchströmung mit $\mathrm{NaCl}+\mathrm{CaCl} 2$ Zunahme bis $20 \mathrm{~mm}$ (Frequenz constant), Herzaction arhythmisch durch Auftreten von Extrareizen am Ventrikel, die auch auf den Vorhof übergehen; dann Abnahme der Contractionen, Ventrikel schlagen öfter als die Vorhöfe, sehr schwache Herzthätigkeit. Ring ersche Lüsung bewirkte sehr spät Zunahme bis $9 \mathrm{~mm}$ Höhe.

Bei einer zweiten Durchströmung mit $\mathrm{NaCl}+\mathrm{CaCl}_{2}$ abermals Zunahme von 10 auf $27 \mathrm{~mm}$ (nach $2^{1 / a^{\prime}}$ ), hierauf ziemlich plötzliche Abnahme, nach $5^{\prime}$ Dauer der Durchspülung trat ein Stillstand auf, normale Ringer'sche Lösung ergab jetzt nur schwache Herzthätigkeit. Dagegen wurde durch eine Injection von $2 \mathrm{ccm}$ $\mathrm{NaHCO}_{3} 1 / 4 \mathrm{n}$. noch die in Fig. 17 Taf. IV wiedergegebene starke Zunahme der Pulshöhen hervorgebracht.

Der Umstand, dass Zufuhr von $\mathrm{Na}_{2} \mathrm{CO}_{3}$ oder $\mathrm{NaHCO}_{3}$ oder $\mathrm{NaOH}$ die bei Durchströmung mit $\mathrm{NaCl}+\mathrm{CaCl}_{2}$ später auftretende Absehwäehung der Herzthätigkeit beseitigt, weist darauf hin, dass diese Abnahme der Contractionsgrösse auch mit auf den Mangel an Alkali zurückzuführen ist.

Reine Kochsalzlösung bringt, wie für das Froschherz lange bekannt, und von Langendorff auch für das isolirte (blutdurchströmte) Säugethierherz bestätigt wurde, das Herz zum Stillstand.

c) Uebersicht über die nach der zweiten Methode gewonnenen Ergebnisse.

Beim Fehlen von Calcium oder von Natriumbicarbonat oder von Calcium, Kalium und Natriumbicarbonat in der Ringer'schen Lösung trat eine $\mathrm{Abnahme} \mathrm{der} \mathrm{Herzthätigkeit} \mathrm{ein.}$ 
Bemerkenswerth ist, dass - abgesehen von dem Falle des Fehlens des Kochsalzes, in welchem ein physikalisches Moment eine Rolle spielt, - wenn das Calcium in der Lösung fehlte, gleichgültig, ob $\mathrm{K}$ ebenfalls fehlte oder nicht, die Herzthätigkeit rascher abnahm, als wenn alkalifreie Lösung verwendet wurde.

Eine Zunahme der Herzthätigkeit trat nur bei Fehlen von Kalium auf, sei es, dass dasselbe allein oder mit Natriumbicarbonat fehlte; im ersteren Falle war die Zunahme aber bedeutend stärker als im zweiten.

Hinsichtlich der Erklärung der Zunahne der Herzthätigkeit kann in beiden Fällen auf das antagonistische Verbalten von Kalium und Calcium bei directer Injection verwiesen werden. Wir müssen annehmen, dass in der normalen Ring e r'schen Lösung das Calcium durch das Kalium zum Theil in der Wirkung compensirt wird, und dass die Verstärkung bei Fehlen des Kaliums auf die nicht compensirte und dadurch stärkere Wirkung des Caleiums zu beziehen ist.

Dass die Verstärkung bei Fehlen von Kalium allein bedeutender ist als bei Fehlen des Kaliums + Natriumbicarbonat, kann durch zwei Momente bedingt sein: erstens kann das Kalium auch dem Natriumbicarbonat gegenüber sich antagonistisch verhalten; wir hätten es dann bei Fehlen des Kaliums allein mit der uncompensirten, also stärkeren Wirkung zweier Bestandtheile (Ca und $\mathrm{NaHCO}_{3}$ ), beim Fehlen des $\mathrm{K}$ und $\mathrm{NaHCO}_{3}$ mit der uncompensirten Wirkung bloss einer Substanz (des Calciums) zu thun; zweitens kann aber bei Fehlen des $K$ und $\mathrm{NaHCO}_{3}$ das Fehlen des letzteren (Alkalimangel) selbst abschwächend auf die Herzthätigkeit einwirken, so dass die durch die uncompensirte $\mathrm{Ca}$-Wirkung hervorgerufene Verstärkung durch die abschwächende Wirkung des sich geltend machenden Alkalimangels zum Theil paralysirt wird.

Gegen die letztere Annahme könnte eingewendet werden, dass, wie wir oben sahen, der Alkalimangel sich erst allmählich geltend macht; andererseits muss man bedenken, dass wir es hierbei mit einer verstärkten Herzaction zu thun haben, wobei der Mangel an Alkali viel rascher zum Ausdruck kommen kann.

Was die bei Fehlen von Kalium (bezw. auch Kalium und Natriumbicarbonat) nach der Verstärkung schliesslich eintretende Abnahme der Herzthätigkeit anbelangt, so kann dieselbe wohl in beiden Fällen auf die starke Reizwirkung des Calciums bezogen werden. 
Diese lässt sich aber in zweifacher Hinsicht denken; erstens kann sie eine directe Wirkung sein, indem das Herz durch die zu grosse Menge Calcium in einer uns noch nicht bekannten Weise geschädigt wird, andererseits eine indirecte, indem es bei der durch die anregende Wirkung des Ca überaus verstärkten Thätigkeit des Herzens zu rascherem Verlust an Arbeitsmaterial kommt (Ueberarbeitung). Hierfür sprieht der Umstand, dass nach Wiedereinleiten der normalen Ringer'schen Lösung die frühere Stärke der Herzthätigkeit nicht wieder erreicht wird.

Eine Ermüdung in dem Sinne, dass es sich um eine Anhäufung von Dissimilationsproducten handelt, ist in diesem Falle weniger wahrscheinlich, wenn wir in Betracht ziehen, dass, wie wir oben ausgeführt haben, alle in's Herz eingeführten, schädigenden Substanzen bei unserer Anordnung des Versuches verhältnissmässig rasch aus dem Herzen wieder ausgespült wurden.

Die bei Fehlen von Kalium + Natriumbicarbonat später auftretende Abnahme der Herzthätigkeit muss ausser auf die eben angeführten, auch hier giltigen Momente auch noch auf den Alkalimangel bezogen werden, der an sich die Herzthätigkeit abschwächt.

\section{Ersatz des Natriumbicarbonates durch Natriumcarbonat oder Natronlange.}

Nach den mit der Injection von Natriumbicarbonat, Natriumcarbonat und Natronlauge, sowie mit der Durchströmug von alkalifreier Ringer-Lösung gemachten Erfahrungen erschien es, auch im Hinblick auf die später zu besprechenden Angaben anderer Autoren, wünschenswerth, die Ring er'sche Lösung mit Salzlösungen zu vergleichen, die $\mathrm{NaCl}, \mathrm{CaCl}_{2}$ und $\mathrm{KCl}$ im selben Verhältnisse wie die Ring er'sche Lösung, aber statt $\mathrm{NaHCO}_{3}$ bestimmte Mengen von $\mathrm{Na}_{2} \mathrm{CO}_{3}$ bezw. $\mathrm{NaOH}$ enthielten.

a) Die mit $\mathrm{Na}_{2} \mathrm{CO}_{3}$ hergestellte Lösung unterbält die Thätigkeit des mit normaler Ringer'scher Lösung wiederbelebten isolirten Herzens längere Zeit auf gleicher Höhe. Bei gewisser grösserer Concentration an $\mathrm{Na}_{2} \mathrm{CO}_{3}$ erfolgt durch sie zunächst eine Zunahme der Ausschläge, so z. B. trat diese Wirkung bei $0,03 \% \mathrm{Na}_{2} \mathrm{CO}_{3}$ Zusatz (ebensoviel wie $\mathrm{NaHCO}_{3}$ in der normalen Ringer'schen Lösung) auf; im weiteren Verlaufe folgte dieser Verstärkung (siehe folgende Versuche) eine Störung der Herzthätigkeit, Ausfallen einzelner 
Ventrikelschläge und schliesslich Abnahme der Ausschläge, was darauf hinweist, dass die genannte Lösung nach längerer Anwendung schädigend wirkt.

Geringere Concentrationen an $\mathrm{Na}_{2} \mathrm{CO}_{3}(0,02-0,015 \%)$ zeigen diese schädigende Wirkung nicht, doch trat auch hier im Vergleiche zur normalen Ringer'schen Lösung eine geringe Abnahme der Ausschläge bei längerer Durchströmung auf.

b) Aehnliche Beobachtungen wurden bei Verwendung der durch $\mathrm{NaOH}$ alkalisch gemachten $\mathrm{Ring}$ e $\mathrm{r}^{\prime}$ schen Lösung als Durchströmungsflüssigkeit gemacht; auch hier kam es bei Verwendung schon geringer Mengen von $\mathrm{NaOH}(0,002-0,01 \%)$ zur Verstärkung der Herzthätigkeit, die relativ lange bei regelmässiger Herzaction anhält; dann traten auch hier bisweilen die oben beschriebenen Störungen ein, die sich wohl auf eine schädigende Wirkung freien Alkalis beziehen lassen.

Bei sehr kleinem NaOH-Gehalte der Ringer'schen Lösung $(0,0005 \%)$ kam es nicht zur Verstärkung, sondern zu einer allmählichen Abnahme der Contractionen; Injection von Natriumcarbonat bewirkte in einem solchen Falle eine bedeutende Zunahme der Ausschläge, was darauf hinweist, dass der Gebalt an Alkali zu gering war.

Aus den Versuchen seien einige hier kurz mitgetheilt.

Versuch Nr. 86. 3. Juli; Hund. Ringer'sche Lösung. Ventrikelcontractionen $35 \mathrm{~mm}$ regelmässig, Frequenz 72 in $1^{\prime}$. Nach $10^{\prime}$ wird RingerLösung mit $0,015 \% \mathrm{Na}_{2} \mathrm{CO}_{3}$ durchströmt; Contractionen blieben $3^{\prime}$ lang kräftig, regelmässig, Höhe $31 \mathrm{~mm}$, Frequenz 72 in $1^{\prime}$. Sodann wieder normale Ring e r'sche Lösung: nach 7' $36 \mathrm{~mm}$; Ringer-Lösung mit $0,02 \% \quad \mathrm{Na}_{2} \mathrm{CO}_{3}$ : nach $21 / 2$ ' Contractionsgrösse $32 \mathrm{~mm}$, nach weiterer $I^{\prime} 30 \mathrm{~mm}$; Ringer-Lösung mit $0,03 \%$ $\mathrm{Na}_{2} \mathrm{CO}_{3}$ : Contractionsgrösse $57 \mathrm{~mm}$, Frequenz 108 in 1'; nach 1' Ringer'sche Lösung: allmähliches Sinken der Contractionsgrösse (nach 1'27 mm, Frequenz 96 in $1^{\prime}$ ). Ausfa'len einzelner Ventrikelschläge; nach weiteren $3 / 4^{\prime} 17 \mathrm{~mm}$ Höhe, es bleibt lange dabei.

Versuch Nr. 84. 1. Juli; Kaninchen. (Vorhof verzeichnet) Ausschläge $7 \mathrm{~mm}$, Frequenz 13 in $5^{\prime \prime}$. Ringer-Lösung mit $0,03 \% \mathrm{Na}_{2} \mathrm{CO}_{3}$ : nach 3 , $8 \mathrm{~mm}$, Frequenz $11^{1 / 2}$ in $5^{\prime \prime}$, sanken dann weiter bis $5 \mathrm{~mm}$ and nach $5^{\prime} 5 \mathrm{~mm}$, erholten sich aber auch nach Wiederdurchfluss normaler Ringer'scher Lösung nicht mehr zur alten Grösse.

Versuch Nr. 77. 24. Juni; Hund (s. Fig. 20 Taf. IV). Ringer'sche Lösung Alternans (r. Vorh. u. r. Ventr. verzeichnet), $25 \mathrm{~mm}$ die grössere Ventrikelcontraction, Frequenz 6 in $5^{\prime \prime}$, Temp. $32,5^{\circ}$.

Ringer-Lösung mit 0,002\% $\mathrm{NaOH}$; nach $2^{1 / 2^{\prime}}$ Höhe 26, Frequenz 7, nach 
$2^{1 / 2^{\prime}}$ Höhe $30 \mathrm{~mm}$, Frequenz $8^{1 / 2}$; normale Ring er-Lösung : allmählich Abnahme nach $12^{\prime} 15 \mathrm{~mm}, 8$ in $5^{\prime \prime}$, Temp. $32,5^{\circ}$; später wieder Zunahme.

Nach einiger Zeit dieselbe NaOH - Ring er-Lösung: Nach 21/2' war die Contractionsgrösse ron 10 auf $17 \mathrm{~mm}$ gestiegen, die Frequenz von 6 auf 7 in 5 "; hierauf Abnahme der Ausschläge bis $11 \mathrm{~mm}$. In einem späteren Zeitpunkte wurde, nachdem in Folge Durchströmung des Herzens mit allalifreier Ringer-Lösung die Ventrikelausschläge fast nichts mehr verzeichneten, die Vorböfe noch deutliche $(3 \mathrm{~mm})$ Ausschläge gaben, dieselbe $\mathrm{NaOH}$-haltige Ringer-Lösung durchströmt; nach 12' betrugen die Ventrikelcontractionen $41 / 2 \mathrm{~mm}$, Vorhofcontraction $8 \mathrm{~mm}$, Frequenz 54 .

Versuch Nr. 76. 13. Juni; Hund. $30^{\prime}$ nach Beginn des Versuches mit norm. Ringer'scher Lösung. Contractionsgrösse $7 \mathrm{~mm}$, Frequenz 8 in 5", Temp. $31^{0}$. Durchströmung mit 0,016\% NaOH-haltiger Ringer-Lösung: Contractionsgrösse steigt allmählich von 7 auf $8,10,15,19,20 \mathrm{~mm}$, entspr. die Frequenz von 8 auf 9 , 10, 11 in 5", Temp. constant 31 ${ }^{\circ}$. Nach $2{ }^{1 / 2^{\prime}}$ plötzlich Ausfallen jedes zweiten Ventrikelschlages, 10 Vorh. 5 Ventr. in 5", Höhe $8 \mathrm{~mm}$; trotz Durchströmung mit normaler Ring er'scher Lösung trat keine Erholung mehr ein.

\section{Wirkung der Kohlensäure.}

Mit Rücksicht auf die Möglichkeit, dass das Natriumbicarbonat seine günstige Wirkung durch Abspaltung von $\mathrm{CO}_{2}$ entfalten könnte, was allerdings schon nach den Ergebnissen der mit $\mathrm{Na}_{2} \mathrm{CO}_{3}$ und $\mathrm{NaOH}$ gemachten Versuche nicht wahrscheinlich war, wurden noch einige Versuche über den Einfluss der Kohlensäure angestellt.

Hierbei zeigte es sich, dass Ring er'sche Lösung, durch welche 3 Stunden lang Kohlensäure geleitet worden war, die Thätigkeit des isolirten Säugethierherzens in kurzer Zeit aufhebt.

Schon 25 Secunden nach Umschaltung der mit Kohlensäure gesättigten Ringer'schen Lösung nahmen die Ausschläge ab, das Herz stand still und war auch für mechanische oder elektrische Reize unerregbar, erst 1' $30^{\prime \prime}$ nach neuerlicher Durchleitung normaler R ing er'scher Lösung begann das Herz wieder zu schlagen.

Derselbe Versuch wurde nach $17^{\prime}$ wiederholt, ganz kurz nach dem Wechsel trat der Stillstand ein (Fig. 9 Taf. III), der erst nach 3 ' langer Durchströmung des Herzens mit normaler Ringer'scher Lösung schwacher Herzthätigkeit Platz machte.

Auch als die stark mit $\mathrm{CO}_{2}$ versetzte $\mathrm{R}$ inger'sche Lösung mit doppelt soviel gewöhnlicher R i n g er'scher Lösung gemischt zur Durchströmung verwendet und schliesslich der Kohlesäuregehalt durch weitere Mischung noch stärker herabgesetzt wurde, wirkte die also modificirte Lösung ebenso, nur trat der Herzstillstand nach einem 
entsprechend längeren Stadium abgeschwächter und stark verlangsamter Herzthätigkeit auf, und es kam auch rascher zur Wiedererholung bei Durchströmung mit gewöhnlicher Ring e r'scher Lösung.

Bei der Injection einer künstlich mit $\mathrm{CO}_{2}$ versetzten $\mathrm{Ringer-}$ schen Lösung in kleinen Mengen $(1-2 \mathrm{ccm})$ wurde gleichfalls stets nur Verlangsamung und Verkleinerung der Contractionen beobachtet (Fig. 10 Taf. III), nie traten Erscheinungen auf, welche auf eine erregende Wirkung der Kohlensäure zu beziehen gewesen wären.

\section{Besprechung der gesammten Versuchsergebnisse und der einschlägigen Literatur.}

Zunächst sei, wie schon in der Einleitung hervorgehoben, nochmals bemerkt, dass die Arbeiten der Autoren, welche sich auf die Wirkung der in der Ringer'schen Lösung enthaltenen Salze auf das isolirte Herz beziehen, an Kaltblüterherzen vorgenommen wurden, während meine Untersuchungen am isolirten $\mathrm{S}$ äugeth i erherz ausgeführt wurden. Nur Rusch (32) hatte vorher neben anderen, hier nicht in Betracht kommenden Speisungsflussigkeiten ausser der Ringer'schen Lösung auch alkalische Kochsalzlösung zur Wiederbelebung von Säugethierherzen benützt.

Meine Versuche über die Wirkung des Kaliums auf das isolirte Säugethierherz ergaben, dass dasselbe nur eine abschwächende bezw. lähmende Wirkung auf die Thätigkeit des isolirten Säugethierherzens ausübt und jedenfalls auch direct auf die Muskulatur einwirkt. Dass die Kalisalze Herzgifte sind, ist seit langer Zeit bekannt. Ich verweise auf die Arbeiten der zahlreichen Autoren, die sich mit der Wirkung der Kalisalze an verschiedenen Thieren bei Darreichung per os, bei subcutaner und intravenöser Application beschäftigten. Bei der intravenösen Injection grösserer Dosen beobachteten sie rapiden Druckabfall und Tod, bei kleineren eine kleine Drucksenkung. mit nachfolgender Drucksteigerung. In der Erklärung dieser Erscheinungen im Einzelnen sind die Ansichten noch nicht ganz einig, worauf jedoch hier nicht näher eingegangen werden kann.

Hervorgehoben seien die Arbeiten von Miekwitz (4) und Böhm (6), welche nach Injection sonst letaler Dosen von Kalisalpeter an Katzen durch Thoraxcompression und Einleitung künstlicher Respiration das Thier retteten, indem durch die Herzmassage eine Art Nothkreislauf hergestellt und durch die Vertheilung des 
Kalisalzes im Gesammtblute dasselbe aus dem Herzen zum grössten Theile entfernt wurde. War die Kaliumdosis zu gross gewesen, so gelang diese Restitution nicht, in solchen Fällen wurde die Herzmuskulatur unerregbar gefunden.

Wie oben erwähnt, trat auch bei unseren Versuchen am isolirten Säugethierherzen nach Injection grösserer K-Dosen Unerregbarkeit des stillstehenden Herzens ein; zum Unterschiede von den Versuchen von Böhm kam es aber bei weiterer Durchspülung mit R ing e rscher Lösung zum Wiederschlagen des Herzens, und zwar bei Dosen, welche viel grösser waren (drei Mal und mehr) als die von $\mathrm{B} \ddot{\mathrm{hm}}$ verwendeten. Wir konnten die Herzen von Thieren, welche durch intravenöse Injection sehr grosser K-Dosen getödtet worden waren, bei Durchspülung mit Ringer'scher Lösung wieder zum Schlagen. bringen und zu Versuchen ebenso gut benützen wie nach dem Verblutungs- oder Erstickungstode.

Wir haben uns übrigens auch davon überzeugt, dass an dem mit verdünnten Blute (2 Theile Ringer-Lösung, 1 Theil Blut) gespeisten isolirten Säugethierherzen hinsichtlich des Wiederschlagens. des Herzens nach Stillstand dureh K-Injection bei längerer Durchspülung dieselben Resultate auftraten, so dass wir es für so gut als sicher annehmen können, dass in den negativen Versuchen von B ö hm das Herz wieder geschlagen hätte, wenn von der Aorta aus durch die Coronargefässe Blut durchströmt worden wäre.

Die Wirkung des $\mathrm{K}$ bei Injection in das mit der Ringer'schen Lösung durchströmte Herz unterschied sich von der bei dem mit Blut gespeisten Herzen nur dadurch, dass bei gleich grosser Dosis von $\mathrm{K}$ der Stillstand an dem letzteren viel länger dauerte; dies ist wohl darauf zurückzuführen, dass, wie schon in der Einleitung bemerkt, die Durchflussmenge des Blutes in der Zeiteinheit bei sonst gleichen Bedingungen kleiner ist als die der Ring er 'schen Lösung, es braucht. daher längere Zeit, bis die Kaliwirkung vorübergeht.

Die Beobachtung von Langend orff (25), dass Injection einer kleinen Menge $\mathrm{KCl}(7,4 \%)$ in das mit Blut durchströmte isolirte Säugethierherz einen Herzstillstand herbeiführte, aus dem das Herz nicht wieder erwachte, können wir aus den eben angeführten Gründen nur darauf zurückführen, dass die Durchströmung nicht genügend lange fortgesetzt wurde, wenn nicht andere, uns unbekannte Momentehierbei etwa mitgespielt haben.

Schon Heubel (17) - und mit weniger vollkommenen Methoden. 
noch vor ihm Guttmann (2) und Ranke (1) - hat das durch Eintauchen in K-Salzlösungen gelähmte Froschherz nach Auslangen des $\mathrm{K}$ durch $0,6 \%$ ige Kochsalzlösung wieder zum Schlagen gebracht; $\mathrm{He}$ u bel nimmt an, dass in diesen Fällen das $\mathrm{K}$ noch keine festeren chemischen Verbindungen mit den Geweben eingegangen ist; verweile das Gift lange Zeit in grossen Dosen im Herzen, so sei keine Restitution mehr möglich.

An dieser Stelle seien auch die Versuche von Lo eb (23) erwähnt, welcher Fischembryonen in $2 \% \mathrm{KCl}$ brachte, worauf Herzstillstand eintrat; nach 44 Stunden in Seewasser gebracht, erholten sich die 5-6 Tage alten Embryonen wieder. Pi ck e ring (27) machte ähnliche Untersuchungen an Vogel- und Säugethierembryonen über die Wirkung von $\mathrm{KCl}$ und beobachtete diastolischen Herzstillstand. Diese Versuche zeigen, dass das Kalium auf den Herzmuskel direct wirkt.

Bottazzi (26) sah bei Auftropfen einer isotonischen $\mathrm{KNO}_{3}$ Lösung auf das blutleere Frosehherz diastolischen Stillstand bezw. Verlangsamung der Schlagfolge und Verstärkung der einzelnen Contractionen eintreten, bei Anwendung hyperisotonischer Lösungen kam es auch zu Stillstand in Systole; war das suspendirte Herz mit Blut gefüllt, so bewirkten auftropfende K-Lösungen niemals Stillstand, sondern nur Verlangsamung und Verstärkung. Auch nach Astolf on i (56) bewirken K-Salze, in grösseren Dosen auf's Herz getropft, Herzstillstand in Diastole, in kleineren Verlängerung der Diastole mit Vergrösserung der Systole, bei weiterem Auftropfen Abnahme der Ausschläge und Schwächung der Herzfunction; die lähmende Wirkung konnte er ebenso wie Bottazzi durch physiologische Kochsalzlösung wieder beseitigen. Da Astolfoni nach Atropin keine Aenderung der Kaliwirkung sah, schloss er daraus, dass das Kalium direct auf den Herzmuskel wirkt. Dieser Schluss geht aber aus dieser Beobachtung nicht zwingend hervor.

Es sei noch auf die analogen Erfahrungen über die Giftwirkungen der Kaliumsalze auf den Skelettmuskel hingewiesen und hervorgehoben, dass Loeb (37) neben anderen Kationen auch den K-Ionen ganz allgemein die specifische Eigenschaft zuschreibt, rhythmische Zuckungen zu unterdrücken; er glaubt, dass das $\mathrm{K}$ in der Zelle mit den Eiweissmolekülen eine Metallverbindung eingehe und dadurch die Eigenschaften des Protoplasmas verändere. -

Von den Autoren, welche sich mit der Untersuchung der Wirkung 
künstlicher Nährlösungen auf das Froschherz beschäftigten, sei zunächst Schücking (43) angeführt, welcher das Kalium wegen seiner schädigenden Wirkung besonders auf das mit Kochsalz erschöpfte Herz von der Verwendung für seine Perfusionsflüssigkeit ausschloss.

Dem gegenüber muss ich mich, auf Grund meiner Versuche, den Anschauungen von Ringer, Göthlin u. A. anschliessen, welche das Kalium für ihre Nährlösungen nicht entbehren konnten.

Ringer (15) fand, dass das $K$ den refractären Zustand, den der Herzmuskel während der Wirkungsdauer eines Reizes gegen weitere Reize ausübt, verlängert, sowie dass $\mathrm{KCl}$ auch eine Verringerung der Reizbarkeit des Ventrikels für elektrische Reize bewirke (16). In späteren Untersuchungen stellte Ringer (16) die Wichtigkeit der Ca- und K-Salze für die Thätigkeit des Froschherzens bei künstlicher Circulation fest und wies bereits auf den Antagonismus derselben hin. Er beobachtete, dass $\mathrm{CaCl}_{2}$, zur physiologischen Kochsalzlösung zugesetzt, das unter der Einwirkung der letzteren still stehende Herz wiederbelebe; doch könne diese $\mathrm{NaCl}-\mathrm{CaCl}_{2}$-Lösung auf die Dauer die Circulation nieht unterhalten, weil die Contraction ver]ängert und die Dilatation zu gering ist; diesen Uebelstand vermag Kaliumzusatz zu beseitigen.

Es sei hier an meine Beobachtungen bei Durchströmung des Säugethierherzens mit K-freier bezw. nur $\mathrm{NaCl}$ - und $\mathrm{CaCl}_{2}$-haltiger Ringer-Lösung erinnert, welche mit denen von Ringer im Wesentlichen übereinstimmen und ergaben, dass das $K$ in der Ring e r'schen Lösung unentbehrlich ist, weil ohne dasselbe die uncompensirte Ca-Wirkung das Herz zwar eine Zeit lang zu sehr verstärkten Contractionen veranlasst, aber schliesslich unter den oben geschilderten Erscheinungen zur Abschwächung bezw. zum Aufhören der Herzthätigkeit führt.

Auch Göthlin (39) fand bei Durchströmung des Froschherzens mit K-freier Salzlösung (die sich von der Ringer'schen Lösung ausser durch eine etwas andere Concentration der in derselben enthaltenen Salze noch durch geringen Gehalt an $\mathrm{Na}_{2} \mathrm{HPO}_{4}$ und $\mathrm{NaH}_{2} \mathrm{PO}_{4}$ unterscheidet), dass hierbei die Contractionen näher der systolischen Lage erfolgen und der diastolische Act unvollkommen wird; er bezeichnet diesen Zustand als Annäherung an oscillatorischen Krampf und bezieht ihn gleichfalls auf die nicht compensirte Wirkung des Calciums. Nebstdem sah Göthlin hierbei eine Störung in 
der Coordination zwisehen Vorhöfen und Kammern derart, dass die letzteren in halbirtem Rhythmus schlugen.

Ich führe ferner u. A. die Untersuchungen von Howell (40) an, welcher die Ansichten Ringer's im Wesentlichen theilt und dieselben Beobachtungen über die Wirkung des Kaliums machte; er fand auch, dass Herzmuskelstreifen (Frosch, Schildkröte) länger in einer Lösung pulsiren, welche $\mathrm{Ca}, \mathrm{Na}$ und $\mathrm{K}$ enthält, als wenn $\mathrm{K}$ fehlt; dieses wirke bei Gegenwart von $\mathrm{Na}$ dem Ca entgegen, es verlangsamt den Rhythmus und verlängert das refractäre Stadium.

Es muss also ebenso wie für das Kaltblüterherz auch für das Säugethierberz daran festgehalten werden, dass man zur Aufrechterhaltung normaler Herzthätigkeit durch künstliche Circulation mit einer Durchströmungsflüssigkeit des Kaliums nicht entrathen kann ${ }^{1}$ ).

Die wichtige Rolle, welche das Calcium in der Speisungsflüssigkeit für das Kaltblüterherz spielt, ist von Ringer erkannt worden, der das in Folge Durchströmung mit Kochsalzlösung stillstehende Herz durch Kalkzusatz wieder zum Schlagen brachte

Göthlin misst den Ca-Ionen die grösste Bedeutung für die Function des Herzmuskels bei; auf seinen Versuch, das Verhalten der Ca- und K-Salze zu den inneren Processen, die bei der Herzthätigkeit vor sich gehen, zu erklären, kann hier nur verwiesen werden; doch sei erwähnt, dass Götblin die Fähigkeit alkalischer Kochsalzlösung, den Herzschlag zu beleben, dem Umstande zuschreibt, dass durch das Alkali das Calcium aus Combinationen von nicht dissociirter Natur gelöst wird; die hauptsächlich auf osmotischem Wege wirksame NaCl-Lösung störe diese Verbindungen nicht, daher höre das Herz bei Durchströmung mit reiner Kochsalzlösung zu schlagen auf, wenn die löslichen Ca-Salze durch Diosmose vollständig entfernt sind. Howell (40) sieht in den Wirkungen der Salze gleichfalls Ionenwirkungen und glaubt, dass besonders die Ca-Ionen als Herzreize anzusehen sind. Eaton(22) fand unter How ell's Leitung, dass Serum, dessen Calciumgehalt ausgefällt ist, den Herzschlag nicht unterbält. Greene (31) beobachtete, dass ein Herzmuskelstreifen

1) Andererseits kann zu hoher Kaligehalt in Speisungsflüssigkeiten schädigend wirken. So beziehen Langendorff (58) und Brandenburg (54) die Unfähigkeit des lackfarbenen Blutes von Kaninchen, das isolirte Frosch-oder Warmblüterherz zum Schlagen zu bringen, auf den hohen Kaliumgehalt desselben. Nach Zusatz von $\mathrm{CaCl}_{2}$ zum defibrinirten Kaninchenblut konnten sie mit demselben das isolirte Froschherz wieder beleben. 
im Serum oder in Ring er'scher Lösung nur dann spontan pulsire, wenn der Kalkgehalt erhöht ist.

Auf die Theorie von Loeb, der glaubt, dass das Calcium an sich zuckungshemmend wirkt, aber in Verbindung mit den an sich giftigen Na-Ionen deren zuckungserregende Wirkung frei werden lässt, soll später in Kürze noch eingègangen werden.

Meine Versuche am Sängethierherzen ergaben, dass das Calcium für das isolirte Säugethierherz unentbehrlich ist, indem bei Verwendung Ca-freier Ringer-Lösung oder reiner bezw. alkalischer Kochsalzlösung das Herz zu schlagen aufhört und nach Wiederdurchleiten einer Ca-haltigen Lösung sich wieder erholt.

Ferner wurde die günstige Wirkung des Calciums auf die Herzcontractionen durch Vermehrung des Ca-Gehaltes der Ring er'schen Lösung (seitliche Injection), indirect bei Verwendung von K-freier Ring er'scher Lösung (und auch einer $\mathrm{NaCl}-\mathrm{CaCl}_{2}$-Lösung) dargethan. In diesen Fällen äussert sich die Ca-Wirkung am isolirten Säugethierherzen in einer Verstärkung der Contractionen und Zunahme der Frequenz.

Auf Erhöhung des Kalkgehaltes ist auch die Wirkung zu beziehen, die wir in Versuchen mit Durchströmung einer mit $2 \%$ Gummi arabicum versetzten Ring er'schen Lösung beobachteten; das Bild (Fig. 15 Taf. III entspricht ganz den bei Verwendung K-freier Ringer-Lösung gewonnenen. Ich erinnere an die gummihaltigen Nährlösungen [Heffter (18), Albanese (19)], deren Wirksamkeit schon Howell auf den Gehalt des Gummis an (aranbinsauren) Kali- und Kalksalzen bezogen hatte; Locke (24) wies dann direct nach, dass die von Albanes e für das Froschherz angegebene Nährlösung $(0,6 \%$ Kochsalz, $2 \%$ Gummi, eine Spur von $\mathrm{Na}_{2} \mathrm{CO}_{3}$ ) ihre Wirkung verliere, wenn man ihr den Kalk entziehe.

Mit meinen Versuchsergebnissen stimmen im Wesentlichen auch die Beobachtungen von Langendorff und Hueck (55) über die Wirkung des Calciums auf das Herz überein, die sie in einer erst kürzlich nach Abschluss meiner diesbezüglichen Versuche veröffentlichten Arbeit mittheilten. Sie fanden, dass das Froschherz bei Speisung mit kalkfreier Ring er'scher Lösung zu schlagen aufhöre, bei Durchströmung mit kalkhaltiger Ring e $r$ 'scher Lösung wieder zu schlagen anfange; ferner beobachteten sie ebenso wie ich durch Erhöhung des Ca-Gehaltes Kräftigung der Pulse, bei zu grosser Concentration einen cardiotonischen Zustand und sprachen die Ansicht 
aus, dass man diesem Ereigniss wahrscheinlich durch Erhöhung des Gehalts der Lösung an Kalium, welches dem Calcium gegenüber als. echter Antagonist wirkt, zuvorkommen könnte.

Langendorff und Hueck sahen dieselbe verstärkende Wirkung des Calciums auch am isolirten mit Blut durchströmten Säugethierherzen auftreten, und Drucksteigerung mit Vergrösserungder Pulse bei intravenöser Injection am intacten Thier. In beiden Fällen beobachteten sie ausserdem eine Zunahme der Frequenz, die am Froschherzen nicht aufgetreten war. Die genannten Autoren meinen nun, dass diese Beschleunigung secundärer Natur sei, und zwar bei der intravenösen Injection durch die Drucksteigerung [bei gelähmten Vagis $\left.{ }^{1}\right)$ ] bedingt, beim isolirten Herzen aber durch die (unter dem Einflusse gesteigerter Herzenergie erfolgende) Steigerung des Durchflusses, welche "die Temperatur des Speisungsblutes. etwas erhöhen und auch für sich die Frequenz in geringerem Maasse steigern kann".

Dieser Deutung kann ich mich bezüglich des von mir sowohl bei der Injection von $\mathrm{CaCl}_{2}$, als auch bei der Durchspülung mit $\mathrm{K}$-freier oder gummihaltiger Lösung erhaltenen, oft bedeutenden Zunahme der Frequenz nicht ansehliessen, ebensowenig auch hinsichtlich der von Langendorff an Säugethierherzen beobachteten Beschleunigung nach vermehrter Ca-Zufuhr.

Denn hinsichtlich der Temperatur der Speisungsfüssigkeit ist bei unserer Anordnung eher der Fall möglich, dass bei Steigerung des Durchflusses die Temperatur abnimmt, weil die Flüssigkeit rascher im System fliesst und daher im Wasserbade weniger hoch erwärmt werden kann.

Hinsichtlich des Einflusses der Steigerung des Blutdurchflusses fanden Magrath und Kennedy (28) an isolirten Säugethierherzen, dass bei stärkerer Speisung der Kranzarterien (durch Aenderung der Druckhöhe) wohl die Energie der Herzcontractionen vermehrt wird, die Pulsfrequenz aber gar nicht oder nur wenig. Aehnlich sind analoge Untersuchungen von Schirrmacher (42) ausgefallen. Hervorgehoben sei noch, dass die Druckschwankungen, mit denen Magrath und Kennedy arbeiteten, unterhalb des von uns (und auch Langendorff) bei den Versuchen an Säugethierherzen stets eingehaltenen ziemlich hohen Druckes liegen; es ist

1) Wodurch die Vaguslähmung herbeigeführt ist, ist nicht angegeben. 
daher nicht anzunehmen, dass die Aenderung im Durchfluss die Beschleunigung bei der Ca-Wirkung hervorruft. Besonders bei der Durchspülung des Herzens mit Ring er'scher Lösung ist die Durehflussmenge in der Zeiteinheit so gross, dass eine Zunahme bei verstärkter Herzaction auf die Frequenz keinen wesentlichen Antheil haben kann.

Auf der myogenen Lehre von der Entstehung der Herzthätigkeit fussend, kann man sich sehr wohl vorstellen, dass das Calcium, gleichwie es die Reactionsfähigkeit des Herzmuskels steigert, auch die Bedingungen sehafft, dass die Reizbildung rascher vor sich geht; beide Umstände können zu einer Zunahme der Schlagfrequenz führen, auch ohne dass das Calcium direct einen Herzreiz bildet ${ }^{1}$ ); in letzterer Hinsicht stimmen wir entgegen Howell u. A. mit Langend orff (55) überein.

Dem Kochsalz, das quantitativ den Hauptbestandtheil der Ringer'schen Lösung bildet, wurde von den meisten Autoren lediglich die Function zugesprochen, den verschiedenen künstlichen Nährlösungen eine den Geweben entsprechende Isotonie zu verleihen. Dass hierzu $\mathrm{NaCl}$ am geeignetsten sei, wurde seit den Untersuchungen von $\mathrm{Nasse}$ (3) allgemein angenommen, der gefunden hatte, dass die Reizbarkeit der Kaltblütermuskeln in einer $0,6 \%$ igen Kochsalzlösung am längsten erhalten bleibe. Diese Lösung wurde daher für den Kaltblütermuskel als indifferent, "physiologisch" angesehen, und demgemäss nehmen auch Ringer, $\mathrm{H}$ ow ell, Albanese, Götblin (l. e.) an, dass eine künstliche Circulationsflüssigkeit für das Froschherz Kochsalz $(0,6 \%)$ enthalten müsse, um eine entsprechende Isotonie herzustellen. $\mathrm{Zu}$ demselben Zwecke erhöhte Rusch den Kochsalzgehalt der Ringer'schen Lösung für das isolirte Säugethierherz auf $0,8 \%$ und $\mathrm{Lock}$ auf $0,9-1 \%$.

Namentlich Albanese hob ausdrücklich als wichtige Bedingung für die Thätigkeit des Froschherzens die Isotonie hervor und glaubte, dass dieselbe statt mit Kochsalz auch mit entsprechend hohem Gummigehalt hergestellt werden könnte, wenn nicht die Consistenz dieser starken Gummilösung ihre Verwendung zur Durchströmung ausschlösse; andererseits fand er isotonische (mit $\mathrm{Na}_{2} \mathrm{CO}_{3}$

1) In ähnlicher Weise lassen sich auch die der Wirkung des Calciums ähnlichen Erscheinungen erklären, welche bei Acceleransreizung oder bei Injection von Nebennierenextract, Digitalin u. s. w. in's isolirte Herz zu beobachten sind. 
alkalisch gemachte) Zuckerlösung für ungeeignet, die Herzthätigkeit aufrecht $z u$ erhalten.

L oeb (34) fand für den Skelettmuskel, dass in Lösungen von Nichtleitern (Zucker, Glycerin) keine rhythmischen Muskelzuckungen auftreten, sondern nur in elektrolytischen Lösungen, so dass er die Fähigkeit, den Skelettmuskel (sowie auch den Herzmuskel) $z u$ rhythmischen Zuckungen zu veranlassen, der Wirkung bestimmter Ionen zuschreibt und glaubt, dass das Eintreten derselben in bestimmte Verbindungen im Muskel die Ursache der Zuckungen ist.

$\mathrm{Zu}$ diesen zuckungserregenden Ionen gehören nach $\mathrm{L}$ o e b auch die Na-Ionen, welche aber an sich (allein in einer Lösung vorhanden) giftig sind; erst in Verbindung mit den an sich zuckungshemmenden Ca-Ionen (antitoxische Wirkung zweiwerthiger Kationen auf die giftige Wirkung eines einwerthigen ist nach Loeb ein allgemeines Gesetz) können sie ihre Wirkung entfalten.

In Consequenz dieser Ansichten gibt es nach Loeb keine Lösung, die bloss eine osmotische Bedeutung für lebende Gewebe hat.

Lingle (38) bestätigte die Theorien von Loeb in Versuchen an ausgeschnittenen Streifen von Schildkrötenherzen auch für dieses; in Lösungen von Nichtleitern schlug dasselbe nicht, auch nicht nach Zusatz von Ca- und K-Ionen. Dieselben Ergebnisse hatte G re e n e (31) (an der Herzspitze der Schildkröte) bei Verwendung von Rohrzuckerbezw. Harnstofflösung.

In einer weiteren Arbeit kommt Lingle (48) zu dem Ergebnisse, dass die Na-Ionen zur Erzeugung der rhythmischen Thätigkeit (von Froschherzstreifen) unerlässlich ist. Nach der Angabe von Lingle unterhält $\mathrm{NaCl}$ und Sauerstoff die rhythmische Thätigkeit ebenso lange als künstliche Salzmischungen, es wäre sonach der Stillstand bei Kocbsalzdurchströmung dem Sauerstoffmangel der NaCl-Lösung zuzuschreiben. Diese Versuche bedürfen noch der Bestätigung am ganzen Herzen von Kalt- bezw. Warmblütern.

Loeb (37) hatte schon früher beobachtet, dass die rhythmischen Contractionen der Medusen in einer Lösung von LiCl, die dem Salzgehalt des Seewassers isosmotisch war und die $\mathrm{K}$ und $\mathrm{Ca}$ in entsprechender Menge enthielt, aufhörten.

Andererseits fand Loeb (34) neben Na-Ionen $u$. A. auch die Li-Ionen befähigt, rhythmische Contractionen der Skelettmuskeln auszulösen. Inwiefern diese mit einander nicht obne Weiteres übereinstimmenden Beobachtungen in Einklang gebracht werden 
können, bleibe dahingestellt. Jedenfalls sei noch darauf hingewiesen, dass Overton (50) in einer sehr ausführlichen und sorgfältigen Versuchsreihe auch dargethan hat, dass die Na-Ionen in ihrer Eigenschaft, die Erregbarkeit der Skelettmuskeln zu erhalten, durch Li-Ionen, und zwar nur durch diese, ersetzt werden können.

Meine bisherigen Versuche mit Kochsalz zeigen, dass stárke Erhöhung des Kochsalzgehaltes schädlich wirkt, dass ferner Fehlen des Kochsalzes in der Ringer'schen Lösung bei sonst gleicher Zusammensetzung die Thätigkeit des Säugethierherzens rasch aufhebt. In beiden Fällen handelt es sich um eine hochgradige Störung des osmotischen Gleichgewichtes, welche zur Erklärung der Erscheinungen genügt.

Ob für das Säugethierherz Na-Ionen zur Aufrechterhaltung der Herzthätigkeit unentbehrlich oder z. B. durch Li-Ionen ganz oder theilweise ersetzbar sind, wäre noch zu untersuchen.

Hinsichtlich des Zusatzes von Alkali ist bereits in älteren Mittheilungen gezeigt worden, dass die Thätigkeit des mit physiologischer Kochsalzlösung zum Stillstand gebrachten Froschherzens durch Zusatz von Natriumcarbonat zur Kochsalzlösung wieder angeregt werden könne (Merunowicz [5]).

Stiénon (8) bestätigte dies und fand, dass durch verschiedene Säuren neutralisirtes Serum auf das Froschberz viel weniger wirksam sei als normales, er hält daher das $\mathrm{Na}_{2} \mathrm{CO}_{3}$ für einen wichtigen Bestandtheil der Nährlösungen.

Gaule (9) kam durch die Beobachtung, dass ausgekochte (also kohlensäureärmere) Soda-Kochsalz-Lösungen wirksaıner waren, zu dem Schlusse, dass im $\mathrm{Na}_{2} \mathrm{CO}_{3}$ das Alkali der für die Sehlagfähigkeit des Herzens wichtige Bestandtheil sei und erhielt die besten Resultate am isolirten Froschherzen mit einer Salzlösung, die mit $\mathrm{NaOH}$ neutralisirt war. G a ule stellte ferner titrimetrisch fest, dass das Alkali bei der Durchleitung durch das schlagende Frosehherz neutralisirt wurde, und zwar durch eine beim Kochen flüchtige Säure (also wahrscheinlich Kohlensäure), sowie durch äusserst geringe Mengen nicht näher bestimmter fixer Säuren.

Rin ge r ermittelte (16), dass eine neutrale, nur $\mathrm{NaCl}, \mathrm{CaCl}_{2}$ und $\mathrm{KCl}$ enthaltende Lösung 1-1/2 Stunden die Thätigkeit des Froschherzens aufrecht erhalten könne, dann müsse Alkali $\left(\mathrm{NaHCO}_{3}\right)$ zur Neutralisirung der im Herzmuskel gebildeten Säure zugeführt werden. Ringer (20) beobachtete ferner, dass Salzlösungen, die aus der 
Luft $\mathrm{CO}_{2}$ absorbirt haben oder künstlich mit $\mathrm{CO}_{2}$ versetzt sind, den Herzschlag nicht unterhalten; war nach dem so herbeigeführten Stillstand die Erregbarkeit der Muskulatur geschwunden, so konnte auch eine Flüssigkeit, die $\mathrm{CO}_{2}$ bindende Stoffe enthielt, keine $\mathrm{Er}$ holung herbeiführen, wohl aber trat eine solche auf, wenn die Erregbarkeit noch nicht vollständig geschwunden war. Bei Neutralisiren von $\mathrm{CO}_{2}$-haltigen Lösungen mit $\mathrm{KOH}$ oder $\mathrm{NaOH}$ sehlug das Herz zwar lange fort, aber es traten tonische Contractionen und Verlängerung der Herzpausen auf.

Diese Beobachtungen stimmen mit der Angabe von Kronecker und M c. Gu ir e (7) überein, dass kohlensäurehaltiges Blut die Thätigkeit des Froschherzens herabsetze; analog sind die Untersuchungen von Saltet (12).

Im Hinblick auf diese Befunde halten die meisten Autoren einen Zusatz von Alkali zu ihren künstlichen Nährlösungen für nothwendig behufs Neutralisirung der vom Froschherzen gebildeten Kohlensäure. Ich nenne $\mathrm{Al}$ banese, der aus diesem Grunde seiner Nährlösung $\mathrm{Na}_{2} \mathrm{CO}_{3}$ zusetzte, und von neueren Autoren Schücking (43), welcher Alkalisaccharat und -fructosat als besonders geeignetes Alkali hält, weil diese, ähnlich wie die Globulin-Alkaliverbindungen, im Blute Kohlensäure binden, ohne die schädigende Wirkung des Alkalis zu äussern.

Gaskell (10) hatte nämlich gefunden, dass freies Alkali die diastolische Ausdehnung verringert und die systolische Zusammenziehung verlängert, und Martius (11) ersetzte aus diesem Grunde das $\mathrm{Gaule}$ 'sche $\mathrm{NaOH}$ in der Salzlösung wieder durch das weniger schädliche $\mathrm{Na}_{2} \mathrm{CO}_{3}$.

Da auch dieses ,zu scharf und reizend" war, ersetzte Rusch (1. c.). für das Säugethierherz das $\mathrm{Na}_{2} \mathrm{CO}_{3}$ in der alkalischen Salzlösung durch $\mathrm{NaHCO}_{3}$, und Locke (24) spricht direct aus, dass er zur Herstellung Ringer'scher Lösung für das isolirte Säugethierherz $\mathrm{NaHCO}_{3}$ und nicht $\mathrm{Na}_{2} \mathrm{CO}_{3}$ verwendete, weil letzteres sehr leicht die charakteristische und fatale Gaskell'sche Alkaliwirkung geben. könne.

Specielle Untersuchungen über den Einfluss des Alkalis und der Kohlensäure auf das Froschherz stellte Göthlin (39) an. Er bestätigt die Angabe Gaule's, dass das NaOH, in verdünnter Lösung der Salzlösung zugesetzt, wirksamer sei als das $\mathrm{NaHCO}_{3}$. Das. Alkali übe einen besonderen Eiufluss auf die Diastole, welche mit 
ungewöhnlicher Schnelligkeit erfolgt; auch waren an der abgeschnürten Herzspitze bei künstlicher Reizung die Ausschläge grösser bei NaOHGehalt der Salzlösung als bei Zusatz von $\mathrm{NaHCO}_{3}$. Da aber jètzt grössere Inductionsschläge nöthig waren, um die Reizung wirksam zu machen, schloss Göthlịn, dass das kohlensäurebindende Alkali die Reizbarkeit der Muskulatur herabsetze. Hierzu sei bemerkt, dass der Schluss auf ein Sinken der Reizbarkeit des Muskels in diesem Versuche desswegen nicht gezogen werden kann, weil die Contractionsgrösse zunahm; denn jener Schluss wäre nur dann richtig, wenn bei der gleichen Reizfrequenz und gleichen Contractionsgrösse stärkere Inductionsschläge zum Wirksamwerden nöthig gewesen wären.

Loeb (34) erblickt die Bedeutung des Alkalis in der Wirkung der Hydroxylionen, welche förderlich auf die Entstehung rhythmischer Contractionen einwirken.

Wie Langendorff bei Besprechung der Ansichten über die Bedeutung des Alkalizusatzes (Ergebn. der Physiol. 1902 S. 308) richtig bemerkt, könnte die Auffassung von Loeb für das $\mathrm{NaOH}$ und $\mathrm{Na}_{2} \mathrm{CO}_{3}$ zutreffen, hinsichtlich des $\mathrm{NaHCO}_{3}$ aber wohl nicht, weil man nicht annehmen könne, dass das saure Salz Hydroxylionen abspalte.

Der von Langend orff ausgesprochenen Vermuthung, dass das Natriumbicarbonat seinen günstigen Einfluss einer Abspaltung von $\mathrm{CO}_{2}$ verdanke, kann ich nicht beistimmen. Langend o rff verweist auf $\mathrm{Oehrwall}$, welcher nach seiner Meinung gezeigt habe, dass $\mathrm{CO}_{2}$ die Erregbarkeit des Herzmuskels steigere. Dazu sei bemerkt, dass es sich in den Versuchen von Oehrwall (29) nicht um directe Kohlensäurevergiftung handelte, sondern um Erstickung, herbeigeführt durch Vertauschung der O- durch eine H-Atmosphäre, so dass die nur im ersten Erstickungsstadium beobachtete anfängliche Steigerung der Erregbarkeit nicht ohne Weiteres auf die $\mathrm{CO}_{2}$ bezogen werden kann.

W. Straub (44) hat zwar bei seinen Versuchen über die Wirkung der Kohlensäure auf das Froschherz angegeben, dass der Ventrikel des in $\mathrm{CO}_{2}$-Atmosphäre schlagenden Froschherzens anfangs eine Steigerung der Erregbarkeit zeige, da der Normalschwellenreiz früher wirksam wurde. Diese Deutung seiner Versuche ist jedoch aus principiell denselben Gründen nicht zulässig, die wir oben gegenüber der Annahme Göthlin's anführten, dass die mit $\mathrm{NaOH}$ alkalisirte Salzlösung die Reizbarkeit des Herzmuskels herabsetze. 
Denn auch in den Versuchen von Straub hatte sich die Contractionsgrösse geändert, und zwar hatte sie abgenommen.

In meinen Versuchen üher den Einfluss der Kohlensäure auf das Säugethierherz (siehe S. 301) trat bei Injection (Methode I) geringer Mengen $\mathrm{CO}_{2}$-haltiger Ringer'scher Lösung stets Verlangsamung und Abschwächung der Herzthätigkeit ein; bei Durchströmung (Methode II) des Herzens mit $\mathrm{CO}_{2}$-haltiger Ringer'scher Lösung trat dasselbe ein oder bei stärkerem $\mathrm{CO}_{2}$-Gehalt - nach einem längeren oder kürzeren Stadium von Verlangsamung und Abschwächung Herzstillstand und Unerregbarkeit des Herzmuskels auch für künstliche Reize.

Diese Beobachtungen stimmen mit den entsprechenden Angaben von Straub für das in Kohlensäureatmosphäre schlagende Froschherz überein.

Die Versuche von Göthlin, die, wie Langendorff an anderer Stelle (a. a. 0. S. 300) bemerkt, dargethan haben sollen, dass $\mathrm{CO}_{2}$ den Herzscblag verstärke, beziehen sich auf ganz besondere Bedingungen, Göthlin fand, dass ein mit alkalischer Salzlösung durchströmtes Froschherz in reiner O-Atmosphäre weniger kräftig schlägt als in einer $7 \% \quad \mathrm{CO}_{2}$ enthaltenden 0 -Atmosphäre. Dies beweist noch nicht, dass die Kohlensäure den Herzschlag verstärke, denn dies trat nur unter den von Göthlin gewählten besonderen Bedingungen ein.

Göthlin zieht aus seinen Beobachtungen nur den Schluss, dass Kohlensäure bei gleichzeitiger Anwesenheit von Sauerstoff und kohlensäuregebundenem Alkali nicht die scbädliche Wirkung ausübt wie eine mit Kohlensäure behandelte carbonatfreie Lösung bei gleichzeitigem Fehlen oder Mangel an Sauerstoff. Totale Aufhebung der $\mathrm{CO}_{2}$-Tension fand Göthlin sogar für schädlich, weil sie von herabgesetzter oder aufgehobener Irritabilität begleitet wird.

Nach Göthlin berechtigen ihn seine Versuche weiter zu dem Schlusse, dass das Alkali "auch in der Form von Bicarbonat" wirksam sein könne, d. h. ohne Kohlensäure chemisch zu binden, und er nimmt an, dass das Bicarbonat die nicht flüchtigen sauren Producte der Verbrennung unscbädlich macht, welche, obgleich in geringer Menge gebildet, in ihrem unverändertem Zustande desto nachtheiliger auf die Function der Gewebe einwirken können.

Da ich einen directen günstigen Einfluss der Kohlensäure auf die Herzthätigkeit nicht beobachten konnte, da ferner bei Injection 
von $\mathrm{Na}_{2} \mathrm{CO}_{3}$ und $\mathrm{NaOH}$ ebenso wie bei der von $\mathrm{NaHCO}_{3}$ Verstärkung der Herzaction erfolgte, kann ich die Wirkung der letzteren nicht auf $\mathrm{CO}_{2}$-Abspaltung beziehen. Angesichts der Experimente von Götblin, welche zeigen, dass ein gewisser Gehalt an Kohlensäure nicht schädlich wirkt, möchte ich die Wirkung des Alkalis in der Durchströmungsflüssigkeit nicht auf Bindung von Kohlensäure beziehen, sondern eher der von Göthlin ausgesprochenen Ansicht beipflichten, dass das Alkali zur Neutralisirung fixer Säuren verwendet wird, obwohl für diese Ansicht Beweise nicht vorliegen.

Damit könnte anch die von mir beobachtete lange Dauer der Wirkung einer Injection von $\mathrm{NaHCO}_{3}, \mathrm{Na}_{2} \mathrm{CO}_{3}$ oder $\mathrm{NaOH}$ in $\mathrm{Zu}$ sammenhang gebracht werden, sowie auch die Thatsache, dass die Wirkung injicirten Alkalis an Säugethierherzen stärker war, die schon länger mit Ringe $r$ 'scher Lösung durchströmt geschlagen hatte.

Dagegen wäre die Beobachtung, dass auch an frischen Herzen die genannten Stoffe ebenfalls verstärkend wirken, nicht ohne Weiteres durch die genannte Annahme erklärt. Wahrscheinlich kommt den genannten Stoffen auch eine direct die Herzthätigkeit anregende Wirkung zu.

Von den genannten drei Substanzen wurde für Durebströmungsflüssigkeiten bisher vorzugsweise das Bicarbonat verwendet, nicht, weil es an sich günstiger wirkt als das Carbonat oder $\mathrm{NaOH}$, sondern nur, weil es nicht die schädigenden Wirkungen freien Alkalis entfaltet. Dies geht auch aus den Angaben von Rusch und Locke für das Säugethierherz hervor.

Meine Untersuchungen mit den durch $\mathrm{Na}_{2} \mathrm{CO}_{3}$ bezw. $\mathrm{NaOH}$ alkalisch gemachten $\mathrm{Ringer}$ 'schen Lösungen sprechen dafür, dass das isolirte Säugethierherz ebensogut mit diesen Lösungen schlagend erhalten werden kann. Die schädigende Wirkung, die bei grossen Dosen sofort, bei mittleren später auftritt, ist wohl nur auf den zu grossen Gehalt an freiem Alkali zu beziehen, und ich glaube, dass bei weiterer Herabsetzung der Concentration und Modification der quantitativen Zusammensetzung der anderen Salze der Ringer'schen Lösung, eine mit $\mathrm{Na}_{2} \mathrm{CO}_{3}$ und $\mathrm{NaOH}$ alkalisch gemachte Ring er' sche Lösung, die Herzthätigkeit ebensogut unterhalten wird wie die mit $\mathrm{NaHCO}_{3}$ hergestellte ${ }^{\mathfrak{}}$ ).

1) Uebrigens hat Walde n (35) mit einer derart hergestellten Lösung (dieselbe enthielt $0,003 \% \mathrm{Na}_{2} \mathrm{CO}_{3}$ ) ein mit Kochsalz zum Stillstand gebrachtes Froschherz für mehrere Stunden wiederbelebt. 


\section{Zusammenfassung der wichtigsten Versuchsergebnisse.}

An isolirten Säugethierherzen (Kaninchen, Katze, Hund), deren Thätigkeit vermittelst Durchströmung der Coronargefässe mit Rin g e r scher Salzlösung unterhalten wurde, wurden die Wirkungen der einzelnen Bestandtheile der genannten Lösung auf das Herz studirt, und zwar:

a) durch Injection bestimmter Mengen eines dieser Salze in die Herzcanüle (Erhöhung der Concentration),

b) durch abwechselnde Durchströmung des Herzens mit Ring er scher Lösung einerseits und mit Lösungen, die je eines oder mehrerer Bestand theile der Ring e r'schen Lösung entbehrten, andererseits.

Beide Methoden ergänzen einander und lieferten folgende Ergebnisse:

1. Injection von $\mathrm{Calcium}\left(\mathrm{CaCl}_{2}\right)$ bewirkt Verstärkung und Beschleunigung der Herzaction, wobei die Verstärkung bedeutender ist als die Besehleunigung. Bei Durchströmung von calciumfreier Ringer'scher Lösung nimmt die Contractionsgrösse und Frequenz ab, um nach Wiederdurchleiten gewöhnlicher Ring er'scher Lösung oder nach Injection von Calcium wieder zuzunehmen.

2. Nach Injection von $\mathrm{K}$ ali u $\mathrm{m}(\mathrm{KCl})$ erfolgt bei kleiner Dosis Abnahme der Contractionsgrösse und Frequenz, bei grösserer diastolischer Herzstillstand, wobei die Erregbarkeit der Muskulatur des Herzens je nach der Menge des Kaliums herabgesetzt oder aufgehoben ist.

Die Kaliumwirkung zeigt grosse Aehnlichkeit mit den Erscheinungen bei Vagusreizung, doch wurde bei letzterer wenigstens am Ventrikel des Säugethierherzens niemals Unerregbarkeit der Muskulatur beobachtet. Von der Muscarinwirkung unterscheidet sich die des Kaliums dadurch, dass letztere auch nach Atropininjection auftritt; ferner ist beim Muscarinstillstand der Herzmuskel erregbar. Bei der Application von KCl-Lösung auf den Vagus wurde, abgesehen von einer vorübergehenden Erhöhung der Erregbarkeit, niemals eine Reizung des Vagus, sondern im Gegentheil - bei starken Lösungen nach kürzerer, bei schwächeren nach längerer Zeit - eine Lähmung des Vagus beobachtet, die aber nach Ersatz des $\mathrm{KCl}$ durch 0,8\% ige $\mathrm{NaCl}$-Lösung wieder schwand. 
Bei Weglassen des Kaliums aus der Ringer'schen Lösung kommt es anfangs zu bedeutend vergrösserten und beschleunigten Contractionen, im weiteren Verlaufe aber bei unvollkommener diastolischer Erweiterung zur Verkleinerung der Herzcontractionen.

3. Das antagonistische Verhalten von $\left(\mathrm{KCl}\right.$ und $\left.\mathrm{CaCl}_{2}\right)$ Kalium und Calcium wurde sowohl bei gleichzeitiger Injection von Kalium und Calcium beobachtet, wie auch die Versuche mit $\mathrm{K}$ - bezw. Ca-freien Salzlösungen auf diesen Antagonismus hinweisen.

4. Kochsalz in stärkerer Concentration und grösseren Dosen bewirkt kurzdauernde Abschwächung der Herzthätigkeit. Hierfür kommt ausser einer chemischen besonders die physikalische Wirkung (Hyperisotonie) in Betraeht.

Ringer-Lösung ohne Kochsalz bringt das Säugethierherz zum Stillstand; das Herz zeigt dann Zeichen grober Schädigung, welche zweifellos mit auf der bedeutenden Störung der Isotonie (Hypisotonie) beruht. Inwieweit, abgesehen von diesem physikalischen Moment, das Fehlen der Na-Ionen hierbei eine Rolle spielt, muss dahingestellt bleiben.

5. Injection von Natriumbicarbonat ruft eine Verstärkung der Herzeontractionen hervor; ebenso Injection von Natriumcarbonat und Natronlauge, deren Wirkung noch stärker ist.

Diese Wirkung hält lange an, besonders an Herzen, die nach langer Thätigkeit (bei Durchströmung mit Ringer'scher Lösung) bereits schwächere Contractionen aufweisen. Diese Beobachtung lässt sich durch die Annahme erklären, dass die genannten Alkalien nichtflüchtige sauere Producte, die bei der Herzthätigkeit gebildet werden und dieselbe schädigen, neutralisiren. Da die verstärkende Wirkung aber auch an frischen Herzen auftritt, ist anzunehmen, dass die genannten Stoffe auch direct auf den Herzmuskel wirken.

Natriumcarbonat und Natronlauge entfalten, in stärkeren Dosen injicirt, bei bedentender Verstärkung der Contractionen auch eine schädigende Wirkung auf das Herz.

Ringer'sche Lösung ohne Alkali ergibt allmähliche Abnahme der sonst regelmässig bleibenden Herzthätigkeit. Injection von $\mathrm{NaHCO}_{3}, \mathrm{Na}_{2} \mathrm{CO}_{3}$ oder $\mathrm{NaOH}$ verstärkt die dureh den Alkalimangel kleiner gewordenen Contractionen. Durchströmung mit alkalischer Ringer'scher Lösung führt wieder zur Erholung.

Das Natriumbicarbonat kann in der Ring e $r$ 'schen Lösung durch Natriumcarbonat oder Natronlauge in geringerer Concentration ersetzt 
werden; die Herzthätigkeit ist bei Durchströmung mit durch $\mathrm{Na}_{2} \mathrm{CO}_{3}$ oder $\mathrm{NaOH}$ alkalisirter Ringer-Lösung oft stärker als bei der $\mathrm{NaHCO}_{3}$-haltigen $\mathrm{R}$ inger-Lösung. Ist der Gehalt an $\mathrm{Na}_{2} \mathrm{CO}_{3}$ oder $\mathrm{NaOH}$ zu gross, so kommt es zu der auch bei der Injection dieser Stoffe beobachteten Schädigung der Herzaction, welche auf die Wirkung freien Alkalis zu beziehen ist.

6. Erhöhung des Kohlensäuregehaltes der Ringer'schen Lösung ergibt immer Verlangsamung und Abschwächung der Herzthätigkeit, bei Sättigung der Ringe er'schen Lösung mit $\mathrm{CO}_{2}$ tritt rasch Stillstand des Herzens und Unerregbarkeit desselben auch für künstliche Reize, bei Wiederdurchströmung mit Ring e r'scher Lösung allmählich zunehmende Herzaction auf.

Injection kleiner Mengen mit $\mathrm{CO}_{2}$ gesättigter Ringer'scher Lösung bewirkt Verlangsamung und Verkleinerung der Contractionen, niemals auf Erregung zu beziehende Erscheinungen.

7. Die in der Ringer'schen Lösung enthaltenen Salze bezw. ihre Kationen sind für die Thätigkeit des isolirten Säugethierherzens unentbehrlich (womit nicht gesagt sein soll, dass sie nicht durch ähnlich wirkende Kationen der entsprechenden Gruppe ersetzt werden können); sie sind eine Bedingung für die Wiederbelebung und Aufrechterhaltung der Herzthätigkeit in demselben Sinne, wie es ein bestimmter Wärmegrad und ein bestimmter Sauerstoffgehalt der Flüssigkeit ist, ohne in der Concentration, in welcher sie sich im Blutserum befinden, selbst Herzreize zu sein.

Zum Schlusse erlaube ich mir, meinem hochverehrten Chef, Herrn Prof. H. E. He ring, unter dessen Leitung ich die dieser Arbeit zu Grunde liegenden Thierversuche ausgeführt habe, für die hierbei mir gewidmete Unterstützung mit Rath und That, nicht minder auch für die mir bei Abfassung dieser Arbeit in reichem Maasse gewährte werthvolle Mithilfe meinen wärmsten Dank abzustatten.

\section{Literatur.}

1) 1864. J. Ranke, Untersuchungen über die chemischen Bedingungen der Ermüdung des Muskels. Arch. f. Anat. u. Phys. S. 343.

2) 1865. P. Guttmann, Experimentelle Untersuchungen über die Wirkungen der Kali- und Natronsalze. Berl. klin. Wochenschr. S. 369 und Virchow's Arch. f. path. Anat. Bd. 35.

3) 1869. O. Nas se, Beiträge zur Physiologie der contractilen Substanz. Pflüger's Archiv Bd. 2 S. 97. 
4) 1874. L. Mickwitz, Vergleichende Untersuchungen über die physiologische Wirkung der Salze und alkalischen Erden. Inaug.-Diss. Dorpat.

5) 1876. Merunowicz, Ueber die chemischen Bedingungen für die Entstehung des Herzschlages. Bericht d. sächs. Akad. d. Wissensch. S. 252.

6) 1878. R. Böhm, Ueber Wiederbelebung nach Vergiftungen und Asphyxie. Arch. f. exper. Pathol. und Pharmak. Bd. 8 S. 68.

7) 1878. Kronecker und Mc. Guire, Ueber die Speisnng des Froschherzens. Verh. d. physiol. Gesellsch. zu Berlin 3, Mai 1878, Arch. f. Anat. u. Phys. S. 321 .

8) 1878. Stiénon, Die Betheiligung der einzelnen Stoffe des Serums an der Erzeugung des Herzschlages. Areh. f. Anat. u. Phys. S. 269.

9) 1878. J. Gaule, Die Leistungen des entbluteten Froschherzens. Ibidem S. 291.

10) 1880. W. H. Gaskell, On the tonicity of the heart and the. blood vessels. Journ. of Phys.

11) 1882. F. Martius, Die Erschöpfung und Ernährung des Froschherzens. Arch. f. Anat. u. Phys. S. 543.

12) 1882. Saltet, Ueber die Ursachen der Ermüdung des Froschherzens. Verh. d. phys. Gesellsch. zu Berlin 28. Juli 1882. Arch. f. Anat. u. Phys. S. 567.

13) 1882. J. S. Ringer, Concerning the influence exerced by each of the constituents of the blood on the contraction of the ventricle. Journ. of Phys. vol. 3 p. 380.

14) 1882. J. S. Ringer, Concerning the action of chloride of sodium etc. on the ventricle of the frog's heart. Practitioner.

15) 1883. J. S. Ringer, On the influence of certain drogs on the period the diminished excitability. Journ. of Phys, vol. 4.

16) 1885. J. S. Ringer, Regarding the effect of the saline ingredients of the blood on the contraction of the heart. Brit. med. Journ. p. 730.

17) 1889. E. Heubel, Die Wiederbelebung des Herzens nach Herzmuskelstarre. Pflüger's Arch. Bd. 45 s. 461.

18) 1892. A. Heffter, Ueber die Ernährung des arbeitenden Froschherzens. Arch. f. exp. Path. u. Pharmak. Bd. 29 S. 41.

19) 1893. M. Albanese, Ueber den Einfluss der Zusammensetzung der Ernährungsflüssigkeiten auf die Thätigkeit des Froschherzens. Arch. f. exper. Path. u. Pharm. Bd. 32 S. 297.

20) 1893. J. S. Ringer, The influence of carbonic acid dissolved in saline solutions on the ventricle of the heart. Journ. of Phys. vol. 14 p. 125.

21) 1893. W. H. Howell and E. Cooke, Action of the inorganic salts of serum, milk, etc. upon the isolated working heart etc. Journ, of physiol. vol. 14 p. 198.

22) 1893. Eat on cit. nach Howell ibid.

23) 1894. J. Loeb, Ueber die relative Empfindlichkeit von Fischembryonen gegen O-Mangel und Wasserentziehung in verschiedenen Entwicklungsstadien. Pflüger's Archiv Bd. 55 S. 525.

24) 1895. F. S. Locke, Towards the ideal arteficial circulating fluid for the isolated frog's heart. Journ. of physiol. vol. 18 p. 332.

25) 1895. O. Langendorff, Untersuchungen am überlebenden Säugethierherzen. I. Pflüger's Arch. Bd. 61 S. 261. 
26) 1896. F. Bottazzi, Sur le mécanisme d'action des sels de potassium sur le coeur. Arch. de Physiol. t. 8.

27) 1896. J. W. Pickering, Experiments on the hearts of mammalian and chick-embryos etc. Journ. of physiol. vol. 20.

28) 1897. G. B. Magrath and H. Kennedy, On the relation of the volume of the coronary circulation to the frequence and fort of the ventricular contraction in the isolated heart of the cat. Journ. of exper. medicine. vol. 2 p. 13.

29) 1898. Hj. Oehrwall, Ueber die periodische Function des Herzens. Skand. Arch. f. Physiol. Bd. 8 S. 1.

30) 1898. W. H. Howell, On the relation of the blood to the antomaticity and sequence of the heart beat. Am. Journ. of Phys. vol. 2 p. 47.

31) 1898. Ch. W. Greene, On the relation of the inorganic salts of blood to the antomatic activity of a strip of ventricular muscle. Americ. Journ. of Physiol. vol. 2 p. 82.

32) 1898. H. Rusch, Experimentelle Studien über die Ernährung des isolirten Säugethierherzens. Pflüger's Arch. Bd. 73 S. 535.

33) 1898. E. Abderhalden, Zur quantitativen vergleichenden Analyse des Blutes. Zeitschr. f. physiol. Chemie Bd. 24 S. 545.

34) 1899. J. Loeb, Ueber Ionen, welche rhythmische Zuckungen der Skelettmuskeln hervorrufen. Beiträge z. Physiol, Festschr. für A. Fick.

35) 1899. E. C. Walden, Comparison of the effect of certain inorganic solutions and solutions containing serumalbumin on the rhythmic contractility of the frog's heart. The Amer. Journ. of Physiol. vol. 3 Nr. 2.

36) 1900. G. Strecker, Ueber das Sauerstoffbedürfniss des ausgeschnittenen Säugethierherzens. Pfüger's Archiv Bd. 80 S. 161.

37) 1900. J. Loeb, Ueber die Bedeutung der Ca- und K-Ionen für die Herzthätigkeit. Pflüger's Archiv Bd. 80 S. 229.

38) 1900. D. J. Lingle, The action of certain ions on ventricular muscle. Americ. Journ. of Physiol. vol. 4 p. 265.

39) 1901. G. F. Göthlin, Ueber die chemischen Bedingungen für die Activität des überlebenden Froschherzens. Skand. Arch. f. Phys. Bd. 7 S. 1.

40) 1901. W. H. How ell, An analysis of the influence of the sodium potassium and calcium salts of the blood on the automatic contractions of heart muscle.

41) 1901. F. S. Locke, Die Wirkung der Metalle des Blutplasmas und verschiedener Zucker a. d. isolirte Säugethierherz. Centralbl. f. Phys. Nr. 26.

42) 1901. L. Schirrmacher, Ueber den Einfluss der Strömungsgeschwindigkeit in den Kranzarterien des isolirten Säugethierherzens auf Stärke und Frequenz des Herzschlages. Inaug-Diss. Rostock.

43) 1901. A. Schücking, Ueber die erholende Wirkung von Alkali-saccharat und Alkalifructosatlösungen auf isolirte Herzen. Arch. f. (Anat. u.) Phys. Suppl.-Bd. S. 218.

44) 1901 W. Straub, Ceber die Wirkung der Kohlensäure am ausgeschnittenen Froschherzen. Arch. f. exper. Path. und Pharmakol. Bd. 45.

45) 1902. A. Kuliabko, Studien über die Wiederbelebung des Herzens. Pflüger's Arch. Bd. 90 S. 461. 
46) 1902. A. Kuliabko, Neue Versuche über die Wiederbelebung des Herzens. Wiederbelebung des menschlichen Herzens. Centralbl. f. Physiol. H. 13.

47) 1902. O. Langendorff, Herzmuskel und intracardiale Innervation. In „Ergebnisse der Physiologie" von Asher u. Spiro 1. Jahrg. 2. Abth.

48) 1902. D. J. Lingle, The importance of sodium chloride in heart activity. Am. Journ. of Phys. Bd. 8 Nr. 2.

49) 1902. J. Loeb, Ueber den Einfluss der Werthigkeit und möglicher Weise der elektrischen Ladung von Ionen auf ihre antitoxische Wirkung. Pflüger's Arch. Bd. 88 S. 68.

50) 1902. E. Overton, Beiträge zur allgemeinen Muskel- und Nervenphysiologie. Pflüger's Arch. Bd. 92 S. 115 u. 346.

51) 1902. H. E. Hering, Sitzungsbericht des Vereins "Lotos" (Biolog. Section). Prager med. Wochenschr. Nr. 52.

52) 1903. H. E. Hering, Ueber die Wirksamkeit des Accelerans auf die von den Vorhöfen abgetrennten Kammern isolirter Säugethierherzen. Centralbl. f. Physiol. H. 1.

53) 1903. O. Langend orff, Ueber die angebliche Unfähigkeit des lackfarbenen Blutes, den Herzmuskel zu ernähren. Pflüger's Arch. Bd. 98.

54) 1903. E. Brandenburg, Die Wirkung des lackfarbenen Blutes auf das isolirte Froschberz. Pflüger's Arch. Bd. 95.

55) 1903. O. Langendorff u. W. Hueck, Die Wirkung des Calciums auf das Herz. P flüg ger's Arch. Bd. 96.

56) 1903. G. Astolfoni, Ricerche intorno all' azione all' azione farmacologica. delle soluzione dei sali di potassio. Arch. int. de Pharmacodyn. et de Thérapie vol. 11,5 u. 6.

\section{Erlänternngen za den Abbildungen der Tafeln II-IV.}

(Zeit in Secunden. Die Grösse der Figuren beträgt $1 / 2$ der Grösse der Originalcurven.)

Tafel II.

Fig. 1. Wirkung der Injection von $7 \mathrm{~cm} \mathrm{KCl}(1 / 10$ norm. $=0,74 \%$ ige Lösung). Hundeherz, r. Vorhof oben, l. Ventrikel unten.

Fig. 2. Wirkung der Injection von $5 \mathrm{ccm} \mathrm{KCl}$ (1/10 norm. Lösung). Hundeherz, 1. Vorhof oben, r. Ventrikel uriten.

Fig. 3. Wirkung der Injection von $2 \mathrm{ccm} \mathrm{KCl} \mathrm{(1/10} \mathrm{norm.} \mathrm{Lösung).} \mathrm{Kaninchen-}$ herz, r. Vorhof.

Fig. 4. Wirkung der Injection von $3,5 \mathrm{ccm} \mathrm{CaCl}_{2}(1 / 10 \mathrm{n} .=1,01 \%$ ige Lösung). Hundeherz, r. Vorhof oben, r. Ventrikel unten.

Fig. 5. Wirkung der Injection von $3 \mathrm{ccm} \mathrm{NaCl}$ norm. Lösung $(=5,8 \%)$. Hundeherz, l. Ventrikel oben, r. Vorhof unten.

Fig. 6. Wirkung der Injection von $3 \mathrm{ccm} \mathrm{CaCl}_{2} \mathrm{x}_{10} \mathrm{n}$. Hundeherz, r. Vorhof oben, l. Ventrikel unten.

Fig. 7 a. Wirkung der Injection von KCl $0,015 \mathrm{~g}$ in $2 \mathrm{~cm}$ Aqua dest.

Fig. $7 b$.

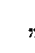

" $"$

" $\mathrm{CaCl}_{2} 0,005 \mathrm{~g}, 2$ ", 
322 E. Gross: Die Bedeutung der Salze der Ringer'schen Lösung etc.

Fig. 8. Wirkung der Injection von $\left\{\begin{array}{l}\mathrm{KCl} 0,015 \mathrm{~g} \\ \mathrm{CaCl}_{2} 0,005 \mathrm{~g}\end{array}\right\}$ in $2 \mathrm{ccm}$ Aqua dest. Hundeherz, r. Ventrikel.

\section{T a fel III.}

Fig. 9. Wirkung der Durchströmung eines Hundeherzens (r. Vorhof oben, r. Ventrikel unten) mit Ringer'scher Lösung, durch die 3 Stunden Ko hlensäure geleitet worden war.

Fig. 10. Wirkung der Injection von $2 \mathrm{ccm}$ derselben Lösung. Hundeherz, Vorhof oben, Ventrikel unten.

Fig. 11. Wirkung der Injection von $\left\{\begin{array}{r}\mathrm{KCl}_{0}^{0,015} \mathrm{~g} \\ \mathrm{CaCl}_{2} 0,045 \mathrm{~g}\end{array}\right\}$ in $2 \mathrm{ccm}$ Aqua dest. Hundeherz, r. Ventrikel.

Fig. $12 a$. Wirkung der Injection von $2 \mathrm{ccm} \mathrm{KCl} 1 / 10 \mathrm{n}$.

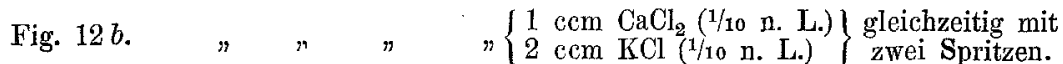

Fig. 12 c. $\quad\{1 \mathrm{ccm} \mathrm{CaCl}(1 / 10 \mathrm{n}$. L. $)\}$ gleichzeitig mit

Kaninchenherz, r. Vorhof.

$"\{1 \mathrm{ccm} \mathrm{KCl} \mathrm{(1/10} \mathrm{n.} \mathrm{L.)}\}$ zwei Spritzen.

Fig. 13. Wirkung der Injection von $4 \mathrm{ccm} \mathrm{NaCl}$ n. L. Hundeherz, r. Ventrikel.

Fig. 14. Wirkung der Durchströmung mit kaliumfreier Ringerlösung.

bei a) Umschaltung von normaler Ringer lösung zu K-freier,

b) " $\quad$ K-freier $\quad$ normaler.

Hundeherz, r. Ventrikel.

Fig. 15. Wirkung der Durchströmung mit 2\% iger gummi-arabicum-haltiger

Ring e rlösung.

$a-b$ gew. Ringer'sche Lösung, $b-c$ Ringer'sche Lösung mit $2 \%$

Gummi, von $e$ wieder gew. Ringer'sche Lösung.

Hundeherz, r. Ventrikel.

\section{Tafel IV.}

Fig. 16. Wirkung der Durchströmung mit calciumfreier Ringerlösung.

bei $a$ wieder Durchströmung mit norm. Ring erlösung.

Hundeherz, 1. Ventrikel.

Fig. 17. Wirkung einer Injection von $2 \mathrm{ccm} \mathrm{Natriumbicarbonat} 1 / 4 \mathrm{n}$. L.

$(=2,1 \%)$. Hundeherz, r. Vorhof oben, 1. Ventrikel unten.

Fig. 18. Wirkung einer Injection von $2 \mathrm{ccm}$ Natriumbicarbonat $1 / 4 \mathrm{n}$. L. $(=2,1 \%)$.

Fig. 19. Wirkung einer Durchströmung mit $\mathrm{NaHCO}_{3}$-freier Ringer-

lösung. . Hundeherz, 1. Ventrikel.

$a-b$ normaie Ringer'sche Lösung, von $b$ an alkalifreie Ringer'sche

Lösung, $c$ nach 1 '20", $d$ nach 50", e Injection von $2 \mathrm{ccm} \mathrm{NaHCO}_{3}$

(1/4 n. L.), $f$ nach 50 ", $g$ nach $1^{\prime}$.

Fig. 20. Wirkung der Durchströmung mit einer $0,002 \% \mathrm{NaOH}$ (statt $\mathrm{NaHCO}_{3}$ ) enthaltenden Ringer'schen Lösung. Hundeherz, r. Vorhof oben, r. Ventrikel unten.

$a-b$ normale Ringer'sehe Lösung, von $b$ an Ringer-Lösung mit $0,002 \% \mathrm{NaOH}, c$ nach $2^{1 / 2}$ ', von $d$ wieder normale Ring er' sche Lösung, $e$ nach $1^{\prime}$. 

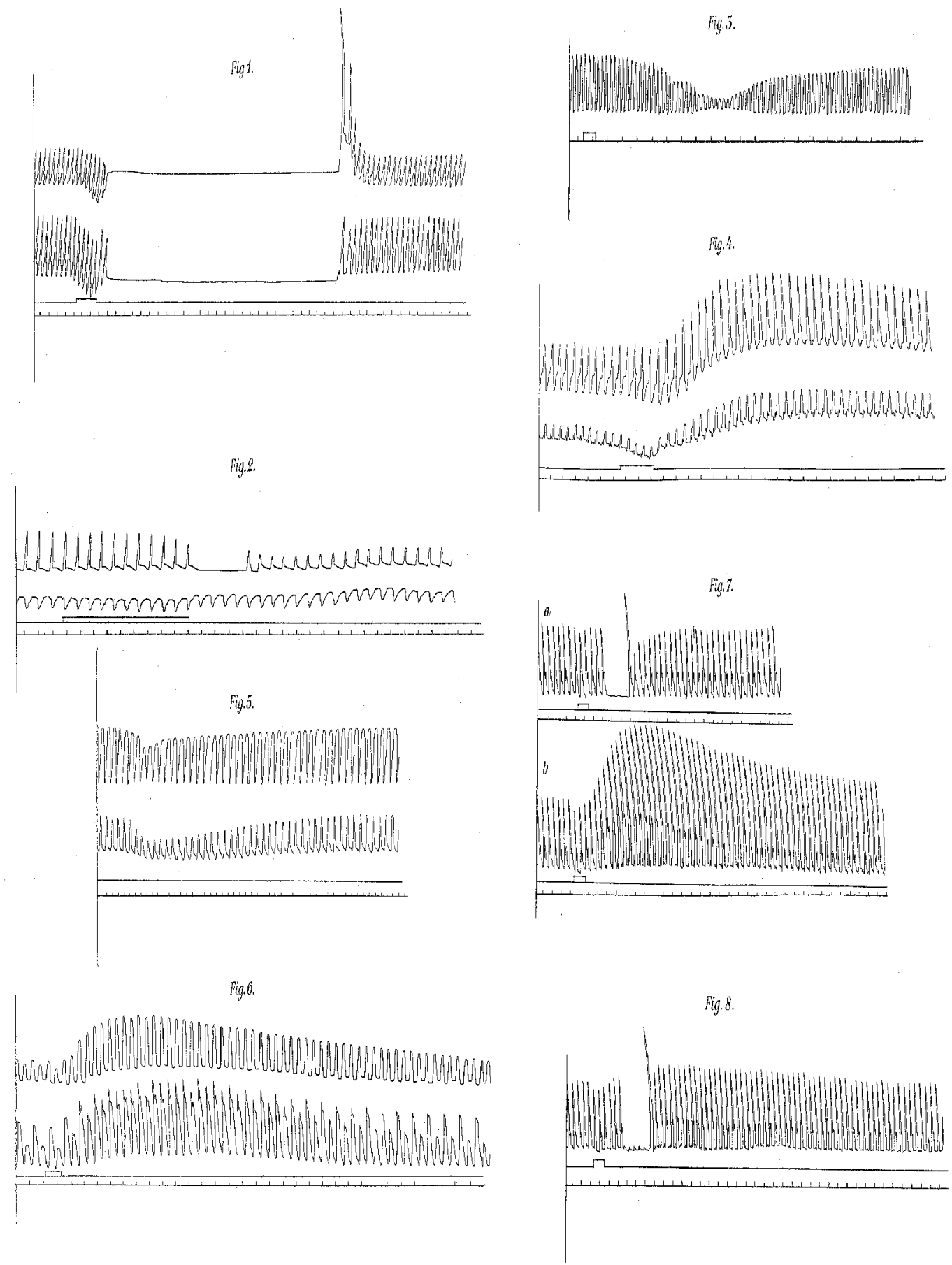


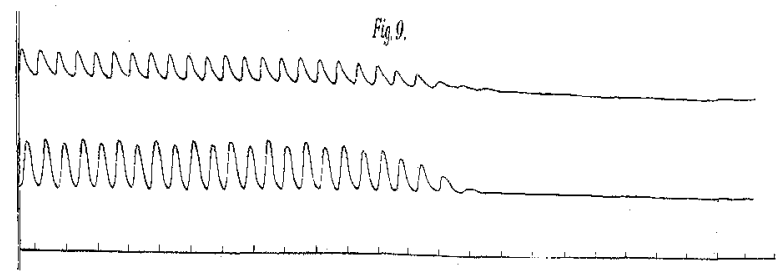

Lumb: If
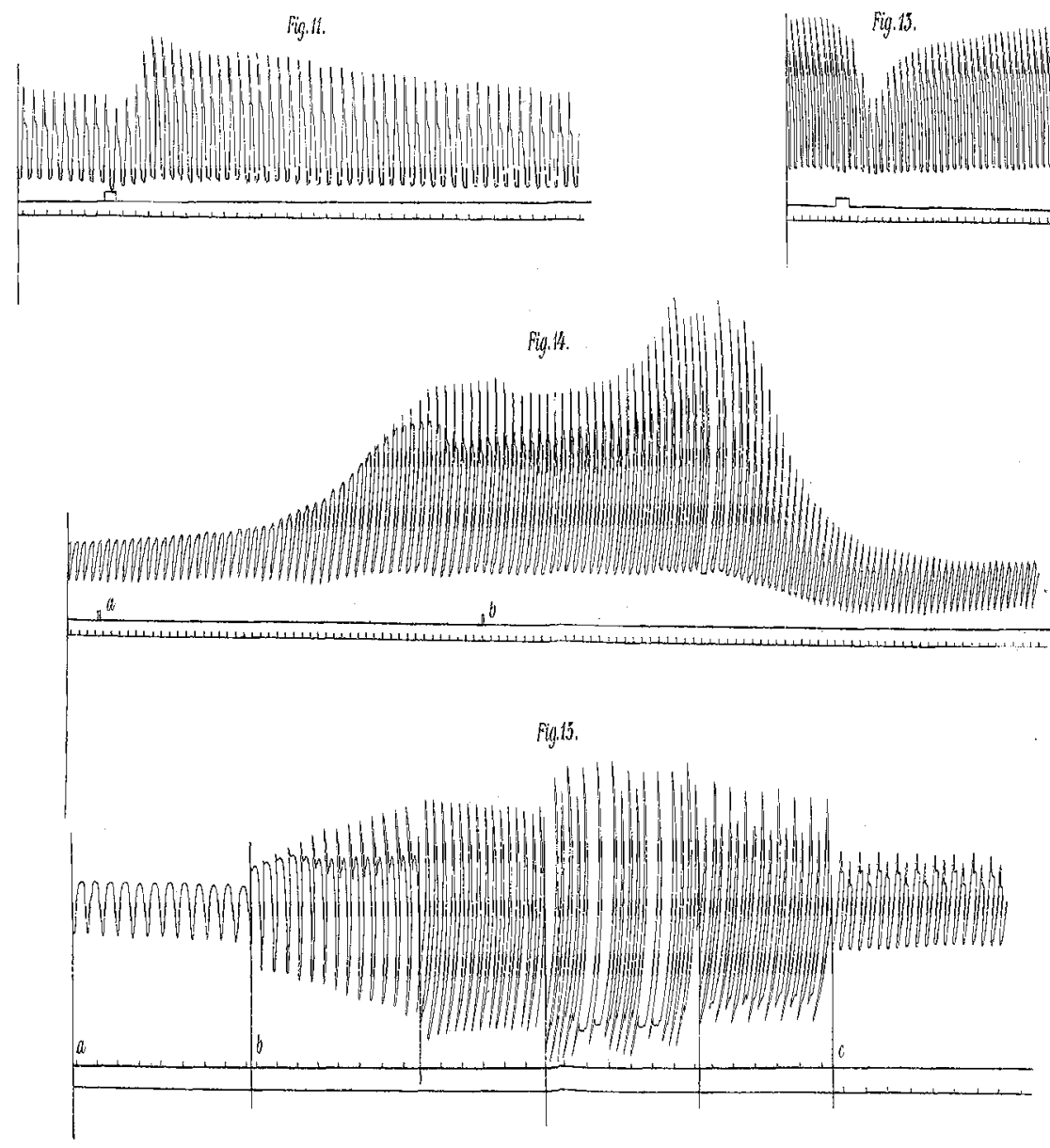

Vethag ven Limil Staviss, Bunill. 


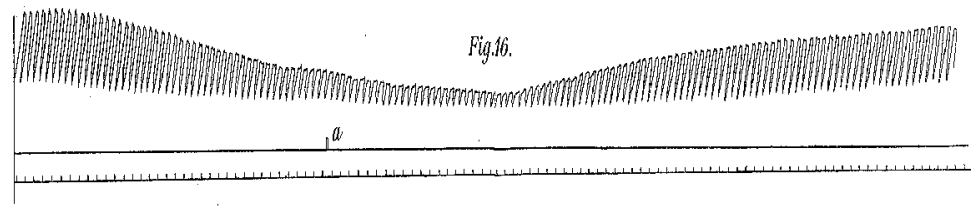

Fip 17

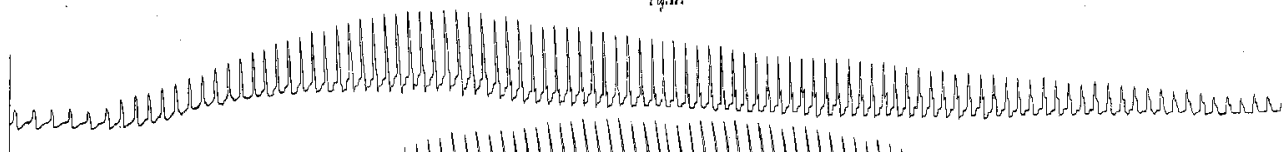
sund

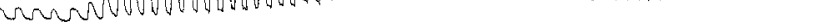

\section{Fig.18.}
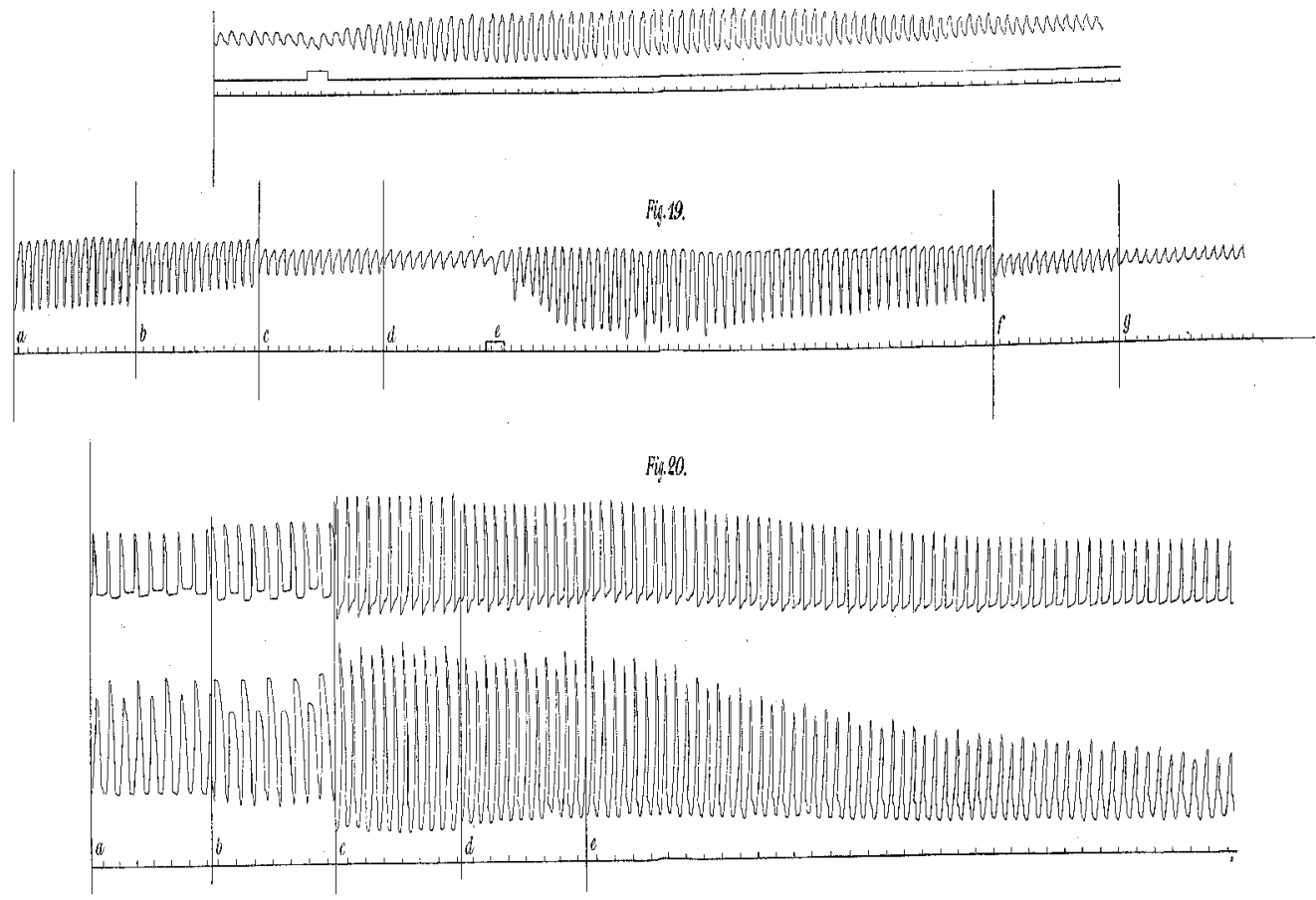